Federal Reserve Bank of Dallas

Globalization and Monetary Policy Institute

Working Paper No. 102

http://www.dallasfed.org/assets/documents/institute/wpapers/2011/0102.pdf

\title{
How have Global Shocks Impacted the Real Effective Exchange Rates of Individual Euro Area Countries since the Euro's Creation?*
}

\author{
Matthieu Bussière \\ Banque de France \\ Alexander Chudik \\ Federal Reserve Bank of Dallas \\ Arnaud Mehl \\ European Central Bank
}

December 2011

\begin{abstract}
This paper uncovers the response pattern to global shocks of euro area countries' real effective exchange rates before and after the start of Economic and Monetary Union (EMU), a largely open ended question when the euro was created. We apply to that end a newly developed methodology based on high dimensional VAR theory. This approach features a dominant unit to a large set of over 60 countries' real effective exchange rates and is based on the comparison of two estimated systems: one before and one after EMU. We find strong evidence that the pattern of responses depends crucially on the nature of global shocks. In particular, post-EMU responses to global US dollar shocks have become similar to Germany's response before EMU, i.e. to that of the economy that used to issue Europe's most credible legacy currency. By contrast, post-EMU responses of euro area countries to global risk aversion shocks have become similar to those of Italy, Portugal or Spain before EMU, i.e. of economies of the euro area's periphery. Our findings also suggest that the divergence in external competitiveness among euro area countries over the last decade, which is at the core of today's debate on the future of the euro area, is more likely due to country-specific shocks than to global shocks.
\end{abstract}

JEL codes: C21, C23

\footnotetext{
* Matthieu Bussière, Banque de France, 31 rue Croix petits champs - 75001 Paris, France. +33-1-42-92-29-21. Matthieu.BUSSIERE@banque-france.fr. Alexander Chudik, Federal Reserve Bank of Dallas, 2200 N. Pearl Street, Dallas, TX 75201. 214-922-5769. alexander.chudik@dal.frb.org. Arnaud Mehl, European Central Bank, Kaiserstrasse 29, 60311 Frankfurt am Main, Germany. +49-69-1344-86-83. Arnaud.mehl@ecb.int. The authors would like to thank Philippe Bachetta, Michele Ca’ Zorzi, Charles Engel, Jean Imbs, Frank Moss, Gernot Müller, Jim Nason, Hashem Pesaran, Adina Popescu, Lucio Sarno, Frank Smets, Pascal Towbin for useful comments on earlier versions of this paper as well as Marcel Fratzscher for support. The views in this paper are those of the authors and do not necessarily reflect the views of the European Central Bank, Banque de France, the Federal Reserve Bank of Dallas or the Federal Reserve System.
} 


\section{Introduction}

Has the creation of the euro changed the way the real effective exchange rates of the countries sharing the single currency adjust to global economic shocks? Such a question is as relevant as ever since the breakout of the global crisis of $2007 / 9$. It is framed in a longer-standing debate, however, on the economic costs and benefits of European and Monetary Union (EMU), which was particularly intense in the run-up to EMU and has never really faded away. The global crisis has indeed given a completely new dimension to the questions as to how euro area countries' real effective exchange rates adjust in the face of global economic shocks, and as to whether the introduction of the euro has changed this adjustment pattern.

Two main views stand out. On the one hand, there is a perception in Europe that the single currency is a shield against global turbulences. Noticeably, euro adoption remains undeniably attractive, as Slovakia's and Estonia's entry as the 16th and 17th member of the euro area in 2009 and 2011 seem to suggest. On the other hand, the crisis has exposed the unsustainability of increasing divergences in the external competitiveness of euro area countries during the first decade of EMU (see Figure 1), which is at the core of today's debate on the future of the euro area. ${ }^{1}$

The literature so far has not considered the way global shocks affect the competitiveness of individual euro area countries. The literature on the impact of EMU has focused largely on studying overall convergence in business cycles and prices within the euro area (e.g. Enders, Jung, and Müller (2009), Canova et al. (2006), Engel and Rogers (2002), and Rogers $\left.(2007)^{2}\right)$, with such studies often finding strong evidence of growing business cycles synchronization and price convergence in the run up to the introduction of the euro in 1999, albeit less so afterwards. There are also studies on the impact of EMU on European integration, focusing both on trade (e.g. Baldwin (2006)) and financial integration (e.g. Cappiello et al. (2009); Coeurdacier and Martin (2009); DeSantis and Gerard (2009); Lane (2006)). Other recent papers have examined the divergences in current account balances within the euro area since the creation of the euro, their determinants and/or implications in the context of growing discussions on intra-euro area imbalances (see e.g. Berger and Nitsch (2010); Jaumotte and Sodsriwiboon (2010); Giavazzi and Spaventa (2010)).

The goal of this paper is to help answer a question for which hard evidence seems to be largely missing, namely "how have global shocks impacted the real effective exchange rates of individual euro

\footnotetext{
${ }^{1}$ In particular, the 16 euro area Finance Ministers noted in early-2010 that "competitiveness divergences and currentaccount imbalances increased steadily in pre-crisis years and have in most cases largely persisted throughout the crisis [...] Given vulnerabilities and the magnitude of the adjustment required, the need for policy action is particularly pressing in Member States showing persistently large current-account deficits and large competitiveness losses" (Eurogroup conclusions on the surveillance of intra-euro area competitiveness and macroeconomic imbalances, Brussels, 15 March 2010).

${ }^{2}$ European Commission (2008) and European Central Bank (2008) provide thorough surveys.
} 
area countries since the euro's creation?". Our focus on global shocks is motivated by the heated debates that preceded the launch of the euro. At that time, the impact of asymmetric shocks and the asymmetric effects of common shocks were heavily discussed. It was feared that if euro area countries were to be hit by global shocks with asymmetric effects, diverging patterns of macroeconomic performances could have adverse implications in a monetary union in which some of the conditions of an optimum currency area (e.g. free labour mobility, price and wage flexibility, and the existence of fiscal transfers) were not met. A decade after the creation of the euro, it is time to assess whether these concerns were justified. We also focus explicitly on real effective exchange rates as a measure of external competitiveness, because it is an aspect that is crucial in the current debate on the euro area's future, notably since the launch by EU Heads of States and Governments in March 2011 of a 'Euro Plus Pact' (also formely known as a 'Pact for Competitiveness') that aims to address losses of competitiveness among Member States of the area.

The exercise we carry out is non-trivial for three main reasons.

First, even if one can expect the adjustment to global shocks of euro area countries' real effective exchange rates to have converged to some extent after EMU, the much deeper question is: converged to what? There, the spectrum of possible answers is wide open. The adjustment could be now akin to the simple average of euro area countries' patterns of adjustment before the euro; or more like that of the most credible economy before the euro; or like that of a less credible economy. This question could not be answered previously due to limitations in existing econometric models.

Second, roughly half of euro area countries' trade remains with countries outside the euro area and domestic price evolutions have not been identical across the euro area since the start of EMU. ${ }^{3}$ In addition, institutional differences across countries, as well as differences related to the industrial or financial structure of the individual EMU countries could be additional sources of heterogeneity (these differences and their impact on the monetary transmission mechanism are tackled for instance in Mihov (2001)). This suggests that the impact of global shocks on their real effective exchange rates is not necessarily homogenous, ex ante. In fact, much of the recent debate on the cohesion of the euro area was indeed related to the differences in individual countries's real effective exchange rates. By focusing on global shocks specifically, we are therefore able to shed some light on a possible source of divergence in the evolution of euro area countries' competitiveness performance and to assess whether it has come from different responses (or patterns of adjustment) to such particular types of shocks.

Third, from a methodological point of view, estimating vector-autogressive (VAR) models is a natural way to approach our question since exchange rates are highly endogenous and those models are typically used to estimate the impact of shocks. However, a crucial and well-known problem is the dimensionality of the system, encountered even with VAR models including a few variables for a short

\footnotetext{
${ }^{3}$ As to the former aspect, it is important to note that there is heterogeneity among euro area countries in terms of exposure to both overall non-euro area trade and to the various countries and regions outside the euro area.
} 
time horizon. Even if meanwhile the euro area has slightly more than 12 years of existence, we have to model here the real effective exchange rates of 17 euro area countries along with the exchange rates of the rest of the world's economies as a control group. In total, we have over 60 currencies and twenty years of monthly data (the 10 years before the creation of the euro in 1999 and the ten years after). Estimating such a VAR model would be simply impossible with standard techniques, due to a problem traditionally coined in the literature as "the curse of dimensionality". 4

We overcome this problem by resorting to a recent methodology introduced by Chudik and Pesaran (2011b) and later extended by Chudik and Pesaran (2011a) in the context of the analysis of VARs of growing dimensions (so-called infinite-dimensional VARs, or IVARs for short), a methodology that also establishes conditions under which the increasingly used "Global VAR model" developed by Pesaran et al. (2004) is applicable. Chudik and Pesaran (2011b) propose a set of restrictions on the coefficients of the unrestricted VAR that are binding only in the limit (i.e. as the number of variables $N \rightarrow \infty$ ) to shrink the parameter space and deal with the dimensionality problem. These restrictions draw from an economically intuitive notion, that of "neighbourhood effects". The latter is based on the idea that some of the units included in a large VAR model (i.e. in our case some of the over 60 countries' real effective exchange rates) are more important than others and have non-negligible spatio-temporal effects on the other units (referred to as their "neighbours"). On the other hand, the remaining units (referred to as "non-neighbours") are presumably less important and assumed to have negligible individual spatio-temporal effects. ${ }^{5}$

We allow for a very rich set-up for our pre and post-EMU IVARs of real effective exchange rates, where shocks can be transmitted across space and time through various channels. The United States (US) is treated as a dominant unit, given the US dollar's overarching role in global foreign exchange markets. Alongside the US, we allow for the possibility of another source of strong cross-section dependence, whose origin is yet unidentified, and control for its potential impact with cross-section averages of the variables. This aside, each country is allowed to have a specific set of neighbours, which are defined on the basis of bilateral trade and financial linkages. We make no homogeneity assumptions, i.e. all units in our systems are treated as heterogenous. Last, the estimated systems pass a range of specification tests and robustness checks successfully.

We propose several statistics based on Euclidean distance measures between impulse response functions (pre- and post-EMU) to formally compare the transmission of shocks across space and time in the estimated IVARs. Clearly, one could think of a large variety of shocks to consider in our context, but it would be unrealistic to envisage to model all of them. To compare the spatio-temporal dynamic

\footnotetext{
${ }^{4}$ For instance, for a VAR model with three lags, we have in our case 62 (number of variables) $\times 62 \times 3=11532$ parameters to estimate and only 12 (months) $\times 10$ (years) $\times 62=7440$ observations.

${ }^{5}$ Arguably, the aggregated impact of non-neighbours could still be large, depending on the degree of cross-section dependence among the units. Such an aggregated impact is in general important when the cross-section dependence is strong (in the sense defined by Chudik, Pesaran, and Tosetti (2011)), in which case it is possible to control for it by using cross-section averages, an idea originally introduced by Pesaran (2006) in the context of the estimation of large heterogenous panels with a multi-factor error structure.
} 
properties of the two IVAR systems, we therefore focus here on three types of shocks: a global US dollar shock, (non-identified) shocks arising from generalised impulse response functions and a global shock to risk aversion. ${ }^{6}$ A key asset of our approach is that we only need to impose that it is the very same type of shock that hit the two systems, which ensures that we can draw meaningful comparisons between the pre- and post-EMU periods, and thereby assess whether or not the creation of the euro was a major turning point.

The first key result of the paper is that the change in the response pattern of euro area countries' real effective exchange rate after EMU depends crucially on the nature of global shocks. In the face of US dollar shocks, the response of euro area countries' real effective exchange rates has become more similar to that of Germany prior to EMU. In other words, the pattern of adjustment of euro area countries' external competitiveness in the face of US dollar shocks is now akin to that of the economy that issued the anchor legacy currency in Europe prior to EMU. When considering generalized impulse response function shocks, we obtain broadly similar results. But when considering global shocks to risk aversion, the response of euro area countries' real effective exchange rates has become more distant from that of Germany prior to EMU and closer to that of countries such as Italy, Portugal or Spain prior to EMU, i.e. of economies of the euro area's periphery.

Importantly, in the case of both types of global shocks, euro area countries' real effective exchange rates depreciate when the US dollar appreciates after EMU. In our interpretation, this might reflect the fact that the euro has become the globally most relevant alternative to the US dollar as an international currency, with a liquidity unmatched by any of the legacy currencies, and hence the main counterpart to US dollar movements. One of the most noteworthy changes is Germany's response pattern to global risk aversion shocks, from appreciation before EMU - when the Deutsche Mark had a safe haven statusto depreciation after EMU- along with all other euro area countries.

Another key result of the paper is that the response of the real effective exchange rates of countries sharing the single currency in the face of global economic shocks has become more homogeneous since the creation of the euro, and to an extent that is unmatched in the rest of the world. This result is noteworthy given the diverging pattern of individual euro area countries' external competitiveness which has been increasingly discussed since the outbreak of the global crisis of 2007/9. This, in turn, suggests that the divergence in real effective exchange rates observed across the euro area in the first decade of EMU is unlikely to be due to global external shocks with asymmetric effects, but rather to other factors, such as EMU country-specific domestic shocks.

The rest of the paper is structured as follows. After introducing the methodology in Section 2, Section 3 discusses how to compare the impact of shocks in the pre- and post-EMU IVARs. Data and

\footnotetext{
${ }^{6}$ Changes in risk aversion and appetite are regarded as important drivers of foreign exchange markets, not only when it comes to emerging market economies but also, more recently, to advanced economies (e.g. McCauley and McGuire (2009), Adrian, Etula, and Shin (2010)). For a recent discussion of risk aversion shocks, see also Popescu and Smets $(2010)$.
} 
key stylized facts are presented in Section 4, followed by the main estimation and specification test results in Section 5. Section 6 compares the spatio-temporal transmission of shocks before and after EMU, and the last section concludes. The appendix presents supplementary tables and figures.

\section{A high dimensional VAR model with a dominant unit of global real effective exchange rates}

Let $x_{i t}$ denote the real effective exchange rate of country $i$ in period $t$. We treat exchange rates as jointly determined and we suppose that the vector of $N$ real effective exchange rates, $\mathbf{x}_{t}=\left(x_{1 t}, \ldots, x_{N t}\right)^{\prime}$, is given by the following VAR model,

$$
\mathbf{x}_{t}=\mathbf{\Phi} \mathbf{x}_{t-1}+\mathbf{u}_{t}
$$

where $\boldsymbol{\Phi}$ is an $N \times N$ matrix of coefficients and $\mathbf{u}_{t}$ is a $N \times 1$ vector of reduced form errors. We abstract here in the notation from higher order lags or deterministic terms to keep exposition as simple as possible.

Consider now the equation for unit $i$ in system (1),

$$
x_{i t}=\sum_{j=1}^{N} \phi_{i j} x_{j, t-1}+u_{i t} .
$$

In empirical applications, unrestricted VAR models typically include at most five to seven variables. But in our particular case, we have 16 euro area countries plus the rest of the world as a control group, i.e. a sample of over 60 countries' real effective exchange rates. $N$ is therefore over 60 and $T$ is about 120 (a decade of monthly observations). For reliable inference and reasonable parameter estimation, we need however far more observations, such as several decades, if not a hundred years of data. But even in this case, the estimation of an unrestricted VAR would not be an appealing option due to the increasing likelihood of structural breaks in such a longer span of data. A priori, the estimation of an unrestricted high dimensional VAR is therefore impaired by the "curse of dimensionality" problem.

\subsection{Solution to the dimensionality problem}

Several approaches have been proposed in the literature to tackle this problem. We resort here to the methodology developed by Chudik and Pesaran (2011b). This approach consists in putting a set of restrictions (that are binding only in the limit, i.e. as $N \rightarrow \infty$ ) on the coefficients of the unrestricted VAR to shrink the space of parameters. These restrictions draw from an economically intuitive notion, that of "neighborhood effects", which is based on the idea that some of the units included in a large VAR model (i.e. some of the over 60 countries' real effective exchange rates in our case) are more important than others and have non-negligible spatio-temporal effects on other units (referred to as 
their "neighbours"). Conversely, the remaining units (referred to as "non-neighbours") are assumed to be less important and to have negligible individual spatio-temporal effects, i.e. effects which die away at a suitable rate proportional to $N$. The shrinkage of the parameter space (as $N \rightarrow \infty$ ) comes from the fact that it is then sufficient to control for the aggregate spatio-temporal impact of the non-neighbours, an impact which can be simply proxied by cross-section averages of the variables.

In an unrestricted VAR all units would be neighbours, but such a model is too complex to be estimated reliably, which reflects a usual trade-off between model richness and the precision of estimation. ${ }^{7}$ The approach retained here tries to strike a fair balance between these two aspects. More formally, suppose that for a given unit $i$, it is possible to divide the units into neighbours and non-neighbours:

$$
x_{i t}=\underbrace{\sum_{j \in \mathcal{N}_{i}} \phi_{i j} x_{j, t-1}}_{\text {Neighbours }}+\underbrace{\sum_{j \in \mathcal{N}_{i}^{c}} \phi_{i j} x_{j, t-1}}_{\text {Non-neighbours }}+u_{i t},
$$

where $\mathcal{N}_{i}$ is a small index set of neighbours for unit $i$, and $\mathcal{N}_{i}^{c}=\{1, . ., N\} \backslash \mathcal{N}_{i}$ is an index set of non-neighbours. The non-neighbours satisfy the following limiting constraint

$$
\left|\phi_{i j}\right|<\frac{K}{N} \text { for any } j \in \mathcal{N}_{i}^{c}
$$

where $K<\infty$ is a positive real constant. The neighbour coefficients are unrestricted in the sense that $\left|\phi_{i j}\right|<K$ for $j \in \mathcal{N}_{i}$. As shown by Chudik and Pesaran (2011b), these restrictions turn out to be fully sufficient to overcome the dimensionality problem. In particular, the cross-section average $\sum_{j \in \mathcal{N}_{i}^{c}} \phi_{i j} x_{j, t-1} \stackrel{q . m .}{\rightarrow} 0$ if $\left\{x_{i t}\right\}$ is cross-sectionally weakly dependent. In this case, the aggregate spatio-temporal impact of the non-neighbours is negligible and it is possible to estimate the neighbour coefficients by simply ignoring the non-neighbours. If $\left\{x_{i t}\right\}$ is strongly cross-sectionally dependent, then the aggregate spatio-temporal impact of the non-neighbours is generally significant and important for consistent estimation and can be approximated by cross-section averages, in particular.

Moreover, as opposed to a strict separation between neighbours and non-neighbours in (3), one could also allow for a linear combination of the units (i.e. a spatially weighted average) to enter the set of neighbours. This is an approach which we will also pursue below.

\subsection{The IVAR model of real effective exchange rates}

We make the following assumptions about neighbours, non-neighbours and patterns of cross-section dependence. The US is treated as globally dominant, i.e. the influence of its currency, the US dollar, is

\footnotetext{
${ }^{7}$ On the one hand, specifying a relatively parsimonious model often yields strong estimation results, but at the expense of omission bias of key variables if the model is too simple. On the other hand, a more complex model allows for a richer representation of the interactions between variables, but at the expense of estimation precision, due to the loss in degrees of freedom.
} 
unrestricted. Put it differently, the coefficients corresponding to the US dollar are left unrestricted and, as such, shocks to the US currency can have non-negligible spatio-temporal effects on the real effective exchange rate of any other country. This is a reasonable assumption to make given the prominence of the US dollar in the current international monetary system, its overarching role in global foreign exchange markets (see, for instance, Goldberg (2010)), which also rests on the significant importance of the US in the global economy.

The US aside, we allow for an additional source of strong cross-section dependence in the system, which could come, for example, from an unobserved common factor. This source is captured by country-specific cross-section averages of foreign variables, denoted as $\bar{x}_{i t}=(N-1)^{-1} \sum_{j \neq i} x_{j t}$.

We identify the neighbours of a given country $i$ on the basis of the intensity of bilateral trade and financial linkages. We select as neighbouring units those countries that have "strong" such linkages with country $i$. In practice, whenever the share of country $j$ in country $i$ 's total foreign trade or foreign financial exposures exceeds ad-hoc thresholds of $20 \%$ and $30 \%$, respectively, it is considered as a neighbour whose impact on country $i$ is fully estimated. We consider three sets of weights: bilateral trade in goods (constructed from the IMF's DOTS database), bilateral foreign equity exposures and bilateral foreign debt exposures (constructed from the IMF's CPIS database). We denote the set of neighbouring units as $\mathcal{D}_{i}=\left\{j \in\{1,2, . ., N\}, w_{i j}^{t}>\lambda_{a}\right\}$ where $w_{i j}^{a}$, for $a \in\{\operatorname{Tr}, E q, D\}$, is the weight of country $j$ in country $i$ 's total foreign trade or foreign exposure to equities or debt securities, respectively, and $\lambda_{a}$ is the corresponding threshold $\left(\lambda_{T r}=20 \%\right.$, and $\left.\lambda_{E q}=\lambda_{D}=30 \%\right)$. In addition to these selected neighbouring units, we consider three spatially weighted averages which exclude the latter. These spatial averages are denoted as $\bar{x}_{w i t}^{a}$, for $a \in\{\operatorname{Tr}, E q, D\}$ (i.e. indices for the trade, equity and debt weights, respectively) and they are treated similarly as the selected individual neighboring units, i.e. their direct spatio-temporal impact on unit $i$ is estimated fully. ${ }^{8}$

These assumptions lead us to estimate the following country-specific conditional models:

$x_{i t}=\delta_{i}+\sum_{\ell=0}^{p_{i 1}} a_{\ell i} x_{1, t-\ell}+\sum_{\ell=1}^{p_{i 2}} \phi_{\ell i i} x_{i, t-\ell}+\sum_{\ell=0}^{p_{i 3}} c_{\ell i} \bar{x}_{i, t-\ell}+\sum_{j \in \mathcal{D}_{i}} \sum_{\ell=1}^{q_{i j}} \phi_{\ell i j} x_{j, t-\ell}+\sum_{j \in\{T r, E q, D\}} \sum_{\ell=1}^{r_{i}^{a}} d_{\ell i}^{a} \bar{x}_{w, i, t-\ell}^{a}+e_{i t}$,

for $i=2,3, \ldots, N$, where the real effective exchange rate of country $i$ in period $t$ is regressed on a constant, contemporaneous and lagged values of the US dollar's real effective exchange rate (the dominant unit, denoted as country 1), its own lags, contemporaneous and lagged values of crosssection averages (a proxy for an unobserved common factor, if present), lagged values of the individual neighbouring units and spatial averages as defined above. This cross-section-augmented regression is estimated by least squares (LS).

\footnotetext{
${ }^{8}$ Overal, our set of neighbours is $\mathcal{N}_{i} \equiv\left\{x_{i t}, x_{1 t}, \bar{x}_{\text {wit }}^{T r}, \bar{x}_{\text {wit }}^{E q}, \bar{x}_{\text {wit }}^{D}\right\} \cup \mathcal{D}_{i}$.
} 
For the US, the following marginal model is estimated:

$$
x_{1 t}=\delta_{1}+\sum_{\ell=1}^{p_{12}} b_{\ell} x_{1, t-\ell}+\sum_{\ell=1}^{p_{13}} c_{\ell, 1} \bar{x}_{1, t-\ell}+\sum_{j \in \mathcal{D}_{1}} \sum_{\ell=1}^{q_{1 j}} \phi_{\ell, 1 j} x_{j, t-\ell}+\sum_{j \in\{T r, E q, D\}} \sum_{\ell=1}^{r_{1}^{a}} d_{1 \ell}^{a} \bar{x}_{w 1 t}^{a}+e_{1 t},
$$

where it is to be noted that the contemporaneous values of cross-section averages $\bar{x}_{1 t}$ do not enter the marginal model for the dominant unit, as explained in Chudik and Pesaran (2011b).

The number of lags $\left\{p_{i k}\right\}_{k=1}^{3},\left\{q_{i j}\right\}_{j \in \mathcal{N}_{i}}$, and $\left\{r_{i}^{a}\right\}_{a \in\{T r, E q, D\}}$ are selected using the Schwarz-Bayesian criterion, with the maximum lag being set equal to 3 in all cases. The resulting model space is thus quite large. For instance, the number of conditional models for a single country with only one neighboring unit is $3^{7}=2187$. Once estimated on a country-by-country basis, individual models (5)-(6) are stacked and solved together in a large reduced-form VAR model (as originally suggested in the GVAR literature; see Pesaran et al. (2004)). The solved high-dimensional VAR model with a dominant unit can then be used for impulse response analysis in a standard fashion.

It is worth noting that our set of over 60 real effective exchange rates does not constitute a closed system, i.e. we do not have all the currencies that are part of all the baskets used to construct all of the real effective exchange rates. ${ }^{9}$ There is therefore no accounting constraint which can be imposed to our system, which also implies that we can derive impulse response functions only for effective exchange rates, and not for bilateral rates.

\section{Comparison of pre- and post-EMU IVARs}

How do global shocks transmit across space and time in the two high dimensional VAR systems estimated prior and post-EMU? To address these questions, we compare the behaviour of real effective exchange rates in the two systems by means of impulse response analysis. For this purpose, it is worth stressing that identifying "pure" economic shocks is not at all essential. ${ }^{10}$ The only issue that really matters is that it is the same shock (even not identified) which is considered when comparing the two VAR systems, prior and post-EMU. As an aside, it would clearly be a formidable challenge to identify all shocks in our high-dimensional system (as this would require over 1,800 identifying restrictions!) let alone to identify the country origin of these structural shocks in our multi-country set-up.

We study the spatio-temporal transmission of three types of shocks: a US dollar shock, (nonidentified) shocks arising from generalised impulse response functions and a shock to risk aversion.

\footnotetext{
${ }^{9}$ Our main data source for the real effective exchange rates in our sample is the IMF IFS database, which does not disclose details on the composition of their currency baskets and which might also change over time.

${ }^{10}$ Identifying econommic shocks is arguably a traditional challenge in the literature due to e.g. the potential existence of different competing structural models underlying such shocks, or to the difficulty to identify their geographic origin. As to the latter, it is reasonable indeed to assume that different structural shocks, say productivity and monetary policy shocks, are uncorrelated within a closed economy, but not when other economies are considered in the analysis. This therefore makes it even more difficult to identify such shocks in a large system. For a related discussion, see Dees, Pesaran, Smith, and Smith (2010).
} 


\subsection{US dollar shocks}

The first type of shock is a "US dollar" shock, i.e. a shock to the system's dominant unit. Considering this type of shock is a natural choice from an economic perspective, given that a possibly large US dollar depreciation and a disorderly unwinding of global imbalances has often been - and still is regarded as a key risk to the global economy (Obstfeld and Rogoff (2005); Obstfeld and Rogoff (2009); International Monetary Fund (2005); Blanchard and Milesi-Ferretti (2009)) and the exceptional rise in US dollar volatility that occurred during the 2007/9 global crisis.

In constructing impulse response functions, we follow Holly, Pesaran, and Yamagata (2010) who first introduced spatio-temporal impulse response functions in a system with a dominant unit. Consider conditional models (5) and a marginal model (6) for the US. Since conditional models are augmented by contemporaneous and lagged values of $x_{1 t}$ it follows that

$$
\operatorname{cov}\left(e_{1 t}, e_{i t}\right)=0, \text { for any } i=2,3, \ldots, N \text {, }
$$

once a suitable number of lags are included in the individual regressions. The US dollar shock is a generalised impulse response function in the VAR given by (5)-(6) with the restriction (7) imposed in the estimation on the variance-covariance matrix of the residuals $\mathbf{e}_{t}=\left(e_{1 t}, e_{2 t}, \ldots, e_{N t}\right)^{\prime}$.

By contrast with standard generalised impulse response functions in small-scale VARs, the shock to the dominant unit is exactly identified in a large $N$ context if the US dollar is the only source of strong cross-section dependence in the system. Exact identification in this case is given by the statistical assumption of US dollar dominance, and the underlying intuition is the same as for the identification of an unobserved common factor in the approximate single factor model literature. However, if individual units are still strongly cross-sectionally dependent once conditioned on the US dollar and its lags, the US dollar shock is no longer identified. ${ }^{11}$

\subsection{Generalised impulse response function shocks}

The second type of shock we consider are generalised shocks to individual economies. Generalised impulse response functions (GIRF) were proposed in Koop et al. (1996), and developed further in Pesaran and Shin (1998) for VAR models. These shocks are clearly not structural in any sense, but they remain useful to compare the dynamic properties of the two estimated IVARs. Generalised impulse responses have the advantage of being independent from the ordering of the variables in the system, which ensures that the results then obtained are not affected by different orderings, which would be otherwise the case with e.g. the standard Choleski decomposition.

\footnotetext{
${ }^{11}$ See Chudik and Pesaran (2011b) for further details on analysis of systems featuring a dominant unit.
} 


\subsection{Risk aversion shocks}

The third and last type of shock we consider is a shock to risk aversion. Clearly, changes in risk aversion and appetite are regarded as important drivers of foreign exchange markets, not only when it comes to emerging market economies but also, more recently, to advanced economies (e.g. McCauley and McGuire (2009), Adrian, Etula, and Shin (2010)). ${ }^{12}$ We remain somewhat agnostic when identifying such risk aversion shocks and, to that end, impose "weak" sign restrictions on selected currencies. ${ }^{13}$

To the extent possible, we aim to motivate our sign restrictions by taking into account currencies' "typical" behaviour in times of heightened risk aversion. To that end, we consider selected major floating currencies and emerging (presumably riskier) market currencies during major historical episodes of heightened risk aversion in the last 20 years (the so-called G10 group of the most liquid currencies in the foreign exchange markets and two reasonably liquid emerging market currencies, the Korean won and the Polish zloty). Figure A.1 plots the change in the (log of the) Chicago Board Options Exchange Volatility Index (VIX) index together with the episodes corresponding to exceptionally large increases in the latter (i.e. Iraq's invasion of Kuwait in August 1990; Russia and LTCM's crises in August 1998; the 9/11 terrorist attacks in September 2001 as well as Lehman brothers' failure in September 2008). Table A.1 reports the change in the real effective exchange rates of the currencies considered during these episodes and the level of the VIX index. What is striking is that the US dollar, the Japanese yen and the Swiss franc tended to appreciate during these major episodes of exceptionally high risk aversion (although not during Iraq's invasion of Kuwait for the US dollar and the yen), possibly pointing to safe haven effects. On the other hand, the Korean won and the Polish zloty systematically depreciated, possibly reflecting the fact that they are often involved in risk-taking trading strategies which tend to unwind in major episodes of market stress.

In line with this, risk shocks are identified by restricting the signs of the impulse response functions to those where random shock draws lead contemporaneously to a $(i)$ rise in the VIX index, $(i i)$ appreciation in the US dollar, Japanese yen and Swiss franc and (iii) depreciation in the Korean won and Polish Zloty.

\subsection{Comparison of pre- and post-EMU global shock transmission}

In order to assess how the transmission of a given shock differs between the pre- and post-EMU periods, we construct the following statistics based on the notion of euclidean distance between impulse response functions.

The first statistics $\eta_{i}^{\alpha}$ measures how much the impact of a shock on a given country has changed

\footnotetext{
${ }^{12}$ In particular, the exceptional rise in volatility in the US dollar, euro and yen during the 2007/09 global crisis, has been largely ascribed to an unprecedented rise in risk aversion which triggered a massive flight to the safety and liquidity of US dollar-denominated assets and confounded previous scenarios of disorderly unwinding of global imbalances.

${ }^{13}$ Identification with sign restrictions is referred to as "weak" here in the sense that a variety of structural models could satisfy the selected signs.
} 
over time:

$$
\eta_{i}^{\alpha}=\left(\sum_{h=0}^{h_{m}}\left[\mathfrak{g}_{\text {Pre }}^{\alpha}(i, h)-\mathfrak{g}_{\text {Post }}^{\alpha}(i, h)\right]^{2}\right)^{\frac{1}{2}}
$$

where $\mathfrak{g}_{\text {Pre }}^{\alpha}(i, h)$ denotes the impulse response function in the pre-EMU IVAR system to a one-standard deviation shock of type $\alpha$ (i.e. either a US dollar shock, a generalised impulse response function shock or a shock to risk aversion) of country $i$ 's real effective exchange rate and at horizon $h$ (with $h_{m}$ being the maximum horizon considered and set equal to 4 hereafter), while $\mathfrak{g}_{\text {Post }}^{\alpha}(i, h)$ denotes the impulse response function to the same type of shock in the post-EMU IVAR system.

The null hypothesis tested is that the impact of a shock of type $\alpha$ is unchanged after the creation of the euro, i.e. the euclidian distance is nil:

$$
H_{0}: \eta_{i}^{\alpha}=0
$$

We use bootstrap replications to compute critical values for $\eta_{i}^{\alpha}$, where the replications used to compute $\mathfrak{g}_{\text {Post }}^{\alpha}(i, h)$ are calculated on the basis of the data generating process from the estimated pre-EMU IVAR system, and under the hypothesis of no break in coefficients and variances.

The second statistics $\xi_{i j}^{\alpha}$ measures how different the impact of a shock on a country after EMU is from that on a benchmark country before EMU:

$$
\xi_{i j}^{\alpha}=\left(\sum_{h=0}^{h_{m}}\left[\mathfrak{g}_{\text {Pre }}^{\alpha}(i, h)-\mathfrak{g}_{\text {Post }}^{\alpha}(j, h)\right]^{2}\right)^{\frac{1}{2}} .
$$

For instance, taking Germany as the pre-EMU benchmark country, i.e. $i=D E$, the statistics helps to measure whether the impact of a shock of type $\alpha$ on a given country after EMU has become closer to the impact it had on Germany before EMU (in other words, whether the pattern of adjustment of country $j$ 's external competitiveness in the face of global shocks has converged after EMU to Germany's pattern before EMU).

The null hypothesis tested is whether the impact of a shock of type $\alpha$ on country $j$ relative to that of benchmark country $i$ before EMU has become smaller after EMU:

$$
H_{0}: \xi_{i j}^{a} \leq\left(\sum_{h=0}^{h_{m}}\left[\mathfrak{g}_{P r e}^{\alpha}(i, h)-\mathfrak{g}_{P r e}^{\alpha}(j, h)\right]^{2}\right)^{\frac{1}{2}}
$$

Again, critical values for $\xi_{i j}^{a}$ are computed by bootstrap replications where the replications $\mathfrak{g}_{\text {Post }}^{\alpha}$ are computed on the basis of the data generating process for the estimated pre-EMU IVAR system (and under the assumption of no structural break).

These measures of euclidian distance can be calculated for impulse response functions to a US 
dollar shock and generalised shocks. However, due to the very nature of the identification scheme, they cannot be calculated for impulse response functions to risk aversion shocks as a variety of structural models could indeed satisfy the selected signs. ${ }^{14}$

\section{Data and stylised facts}

Our sample includes monthly data for the period between January 1989 and August 2009, i.e. approximately the decade preceding the creation of the euro and the single currency's first ten years.

For the data on real effective exchange rates, our main source is the IMF IFS database, the broadest publicly available dataset on monthly (consumer price-based) real effective exchange rates. For missing observations, we also use BIS (broad-58 country) real effective exchange rate indices and occasionally construct our own indices for a few countries which were not covered in the IMF or BIS databases. All in all, we have a broad set of 62 countries, including advanced, emerging and developing economies. A detailed description of the data is given in Table A.2.

Figure 1 plots the real effective exchange rate of the euro area countries in log levels. ${ }^{15}$ Real effective exchange rate evolutions have become more similar after EMU. ${ }^{16}$ But some differences in external competitiveness evolutions did persist across euro area countries, which raises the question as to where these differences come from. In relation to this, Table 1 reports the standard deviation of the log-differences of the series pre- and post-EMU. Three striking observations stand out. The alleged 'core' euro area countries (Austria, Belgium, France, Germany, Luxembourg and the Netherlands) had far more stable real effective exchange rates than the other countries (the alleged 'periphery') before EMU. All countries' real effective exchange rate have become more stable since the creation of the euro (with the exception of Ireland), although not identically stable. Only Ireland has had a markedly more volatile real effective exchange rate post-EMU than pre-EMU. Table 1 also reports cumulated changes in real effective exchange rates over 1999-2009 and shows clearly that external competitiveness -measured by this yardstick- deteriorated most in Ireland (by about 30\%), Spain or Greece (by about $20 \%$ ), and least in Germany (by less than 7\%).

We treat real effective exchange rates as stationary in first-differences. Our estimation period is indeed only a decade for each of the two IVARs and unit root tests do not reject the null of a unit

\footnotetext{
${ }^{14}$ For shocks to risk aversion, we follow the literature in summarizing the available information in multiple structural models by reporting median and quantiles of impulse responses obtained through bootstrap replications. It should be highlighted, however, that the median itself is not an impulse response function per se (and generally does not belong to the space of impulse responses). In the same spirit, quantiles cannot be interpreted as confidence intervals in this case and, for the same reason, measures of euclidian distance cannot be calculated.

${ }^{15}$ To ensure comparability between the two estimation periods, we only include in our sample those countries which were members of the euro area from the outset in 1999 (i.e. Austria, Belgium, Finland, France, Germany, Ireland, Italy, Luxembourg, the Netherlands, Portugal, Spain) and Greece, which joined relatively early on (namely in 2001). We therefore discard those new EU Member States which joined later (after 2004), including Slovenia, Slovakia, Malta, Cyprus and Estonia.

${ }^{16}$ Prior to EMU, a large part of the volatility in the relative evolution of REERs across European economies occurred between the late 1980s and the mid-1990s.
} 
root in levels in our data. ${ }^{17}$ This is also in line with several well-established theoretical reasons for the presence of non-stationarity in real effective exchange rates, such as Balassa-Samuelson effects.

Turning to other variables, foreign trade weights are constructed from the IMF DOTS database on the basis of the average of bilateral imports and exports from 2004 to 2006. Financial weights are constructed from the IMF CPIS database as the average of bilateral foreign assets and liabilities (both for equities and debt securities) over 2000-2006.

\section{Salient estimation and specification test results}

The estimation results from our two IVAR models appear reasonable and a battery of specification tests suggest that our models are well specified and characterise rather well the complex interactions and dynamics of our high-dimensional real effective exchange rate systems. Due to the very large amount of regressions involved, we only review in the following the main estimation and specification tests results.

\subsection{Stability of the models}

The estimated models are stable. Figure 2 plots by descending order the absolute value of the largest 60 eigenvalues of the estimated IVAR systems' corresponding companion matrix (out of over 186) and shows that they all stand well below unity. The single largest eigenvalues equal 0.64 (pre-EMU) and 0.82 (post-EMU), which also suggests that shocks to real effective exchange rates in the two systems tend to die out somewhat rapidly.

\subsection{Significance of the coefficients}

Our prior that some channels of transmission of shocks in the two systems are more important than others is largely confirmed (see Table 2). Most notably, the assumption that the US is a dominant unit is vindicated: the US dollar has statistically significant spatio-temporal contamporaneous effects on about two-third of the countries' real effective exchange rates before EMU, and on about four-fifth thereof after EMU. Other sources of strong cross-section dependence, such as an unobserved common factor, also seem to play a role, most notably after 1999. Contemporenous cross-section averages are indeed found to be statisically significant for over half of the countries' real effective exchange rates post-EMU. Trade and financial linkages tend to have limited statistically significant spatio-temporal effects (with the exception of foreign equity exposures pre-EMU, which then matter for less than onefifth of the countries). Moreover, there is evidence for some persistence in real effective exchange rate

\footnotetext{
${ }^{17}$ These results are not reported due to space considerations. Even in longer time spans of data, it is common to find unit roots in real effective exchange rates (see e.g. Pesaran et al. (2004)), although for very long periods - such as centuries - there is some evidence of mean reversion, see for instance Taylor et al. (2001). Such very long datasets are available for a handful of currencies, however.
} 
dynamics, since exchange rate lags enter significantly in over half of the two IVAR models' equations. Last, the impact of neighbouring units other than the US is found to be significant for $20 \%$ of the countries considered pre-EMU, against about $10 \%$ post-EMU.

These conclusions are broadly confirmed by standard $F$-tests for the joint significance of contemporaneous and lagged values of the explanatory variables. Figure 3 and Figure 5 report the test results for each of these variables and for both estimation periods. The size of the test is reported on the $x$-axis and rejection rates for the null hypothesis of no joint significance are reported on the $y$-axis. For instance, results for the dominant unit indicate that the null hypothesis of no direct US dollar effect, namely

$$
H_{0}: a_{\ell i}=0 \text { for all } \ell \in\left\{0,1, . ., p_{i}\right\}
$$

is rejected for about half of the countries at the $1 \%$ level of confidence pre-EMU, against $70 \%$ of the countries post-EMU. Overall, the test results confirm that the US, other unobserved common effects and persistence in real effective exchange rate dynamics are significantly present for a large share of the 62 countries we consider, both pre- and post-EMU. Conversely, the influence of the remaining variables (trade and financial linkages, other neighbouring units) is less -if at all- ascertained.

\subsection{Tests for weak exogeneity of the US dollar}

The assumption that the contemporaneous change in the US dollar is weakly exogenous in the equations for the remaining currencies can be tested by using the procedure proposed by Wu (1973). Let $\widehat{e}_{1 t}$ denote the residuals from the estimated model for the dominant unit. We run the following auxiliary regressions for countries $i=2,3, \ldots, N$,

$$
\begin{aligned}
x_{i t}= & \delta_{i}+\sum_{\ell=0}^{p_{i 1}} a_{\ell i} x_{1, t-\ell}+\sum_{\ell=1}^{p_{i 2}} \phi_{\ell i i} x_{i, t-\ell}+\sum_{\ell=0}^{p_{i 3}} c_{\ell i} \bar{x}_{i, t-\ell} \\
& +\sum_{j \in \mathcal{D}_{i}} \sum_{\ell=1}^{q_{i j}} \phi_{\ell i j} x_{j, t-\ell}+\sum_{j \in\{T r, E q, D\}} \sum_{\ell=1}^{r_{i}^{a}} d_{i \ell}^{a} \bar{x}_{w i t}^{a}+\omega_{i} \widehat{e}_{1 t}+e_{i t},
\end{aligned}
$$

which correspond to conditional country models in (5) augmented by the extra term $\omega_{i} \widehat{e}_{1 t}$. Wu's approach consists in testing the significance of $\widehat{\omega}_{i}$ using a standard $t$-test. In practice, if the US dollar was not weakly exogenous, $\hat{\omega}_{i}$ should be statistically significant. This testing procedure is asymptotically equivalent to that of Hausman (1978), which is based on the statistical significance of the difference between instrumental variable and least squares estimates.

A summary of the Wu-Hausman test results for weak exogeneity of the US dollar is reported in Figure 8, which displays rejection rates (i.e. the number of countries for which the null was rejected divided by the overall number of conditional models) for different nominal size of the test. In both estimation periods, i.e. pre- and post-EMU, rejection rates are very close to the nominal size of the 
test, which suggests that there is no evidence against weak exogeneity of the US dollar.

\subsection{Economic meaningfulness (contemporaneous elasticities w.t. US dollar changes)}

The sign and magnitude of the main estimation results are also in line with economic intuition. In particular, when considering the estimated elasticity of the 61 countries' real effective exchange rate with respect to contemporaneous US dollar changes post-EMU (see Figure 6), it is striking to observe that the elasticity for countries such as Saudi Arabia and China, two well-known US dollar peggers, is found to be positive and close to unity, while that for so-called "commodity currencies", which are not pegged to the US dollar, and are often believed by market participants to move inversely with the US dollar (see International Monetary Fund (2008)), is indeed found to be negative and close to -1 .

\subsection{Goodness of fit}

In terms of goodness of fit, the adjusted $R^{2}$ (hereby denoted $\bar{R}^{2}$ ), of country-specific models range from close to 0 to $85 \%$ (see Figure 4 for the post-EMU IVAR). The $\bar{R}^{2}$ for the US marginal model stands at $13 \%$ (pre-EMU) and $18 \%$ (post-EMU). For a majority of the countries considered, $\bar{R}^{2}$ is larger than commonly found in the empirical literature on real effective exchange rates, due to the fact that -in our set of conditional variables- the dominant unit and cross-section averages already capture a large share of the data's cross-section dependence.

\subsection{Residual serial correlation}

We formally test for residual serial correlation using the Breusch-Godfrey test with 4 lags, with the null being no serial correlation and the alternative hypothesis being that errors follow an $\operatorname{ARMA}(p, q)$ process, with $\max (p, q)=4$. There is strong evidence in support of no remaining serial correlation in the residuals, since the null is rejected at the $1 \%$ level of confidence for only two countries in each period (Israel and Romania in the pre-EMU IVAR system; Ecuador and Antigua-Barbuda in the post-EMU IVAR system).

\subsection{Structural breaks}

Last, we test for the existence of possible structural breaks with a large array of tests, including Ploberger and Krämer (1992) maximal OLS cumulative sum (CUSUM) statistics (denoted $P K_{\text {sup }}$ ); its mean square variant $\left(P K_{m s q}\right)$; Nyblom (1989)'s tests for parameter constancy against non-stationary alternatives $(\mathfrak{N})$; the Wald form of Quandt (1960)'s likelihood ratio statistics $(Q L R)$; the mean Wald statistics of Hansen $(M W)$; and Andrews and Ploberger (1994)'s Wald statistics based on exponential averages $(A P W)$. The last three tests are Wald type tests for a single break at an unknown point in time. We also run heterokedasticity-robust versions of these tests. 
Table 3 reports an overview of the tests' results. There is little statistical evidence with which to reject the hypothesis of coefficient stability in the case of $73 \%$ to $92 \%$ (depending on the test) of the equations comprising the IVAR model pre-EMU and in the case of $74 \%$ to $98 \%$ of the equations post-EMU. This order of magnitude is very much in line with results found in the GVAR literature (see e.g. Dées, di Mauro, Pesaran, and Smith (2007)). The non-robust versions of the $Q L R, M W$ and $A P W$ tests, however, show a relatively larger number of rejections. In view of the test outcomes for the robust versions of these tests, the main reason for the rejection seems to be breaks in error variances and not in the parameter coefficients. Once possible changes in error variances are allowed for and robust versions of these three tests considered indeed, the parameter coefficients seem to be reasonably stable. This conclusion is in line with many recent studies that find some evidence of changing volatility as documented, among others, by Stock and Watson (2002), Artis et al. (2006) and Cecchetti et al. (2005). Overall, not surprisingly there is some evidence of structural instability but this seems to be mainly confined to error variances. ${ }^{18}$ To address the possibility of breaks in error variances, we focus on the bootstrap means of the impulse responses in the empirical analysis hereafter.

As a robustness check of these results, we also re-estimate pre- and post-EMU systems with country specific dummies set to capture one-off exceptional events of unusually large exchange rate movements, such devaluations, realignments in the European Exchange Rate Mechanism, etc. A full list of these dummies is reported in Table A.3. The results obtained are largely similar as those without dummies and we therefore focus on the estimation results without dummies hereafter.

\section{Spatio-temporal transmission of shocks before and after EMU}

\subsection{US dollar shocks}

Figure 7 reports the contemporaneous impact of a one standard deviation shock to the US dollar on the real effective exchange rate of the euro area countries, both pre- and post-EMU, along with $90 \%$ confidence intervals computed with 2,000 boostrap replications.

In the decade preceding EMU, the impact of such a shock was significantly diverse across countries. For instance, a typical one-standard deviation appreciation of the US dollar's real effective exchange rate (i.e. about $1.25 \%$ ) was associated with a $0.4 \%$ contemporaneous depreciation of the Deutsche Mark. The currencies from some of the other future euro area members depreciated in tandem, including that of Austria, Belgium, Finland, France, Ireland and the Netherlands, albeit to a smaller extent (i.e. in the order of $0.1 \%-0.3 \%$ ). By contrast, Italy and Greece's real effective exchange rates tended to appreciate, although to an extent that was not significantly different from zero. Those of Luxembourg and Portugal were clearly unaffected. These results are partly reminiscent of a key stylized fact of the

\footnotetext{
${ }^{18}$ Over the two decades we consider, some of the countries in our sample have indeed experienced well-known devaluations, exchange rate regime changes and other large country-specific shock (such as Germany's unification).
} 
1980s related to US dollar shocks. Giavazzi et al. (1986) had found indeed that the Deutsche Mark usually appreciated against other European currencies when the US dollar depreciated in that decade, which would then dampen the effect of dollar shocks on the REER of France and Italy and amplify that on Germany's. Our results for Germany and Italy do confirm this (but not those for France, admittedly).

The picture after EMU is completely different. All of the euro area countries' real effective exchange rates now respond similarly to US dollar shocks, including those of Italy, Greece, Luxembourg and Portugal which used to respond differently before the euro was introduced. According to the estimates, further to a one-standard deviation appreciation of the US dollar's real effective exchange rate (i.e. again about $1.25 \%$ ), the real effective exchange rate of all euro area countries depreciate contemporaneously within a range of $0.3 \%-0.6 \%$. In other words, the pattern of adjustment of euro area countries' external competitiveness in the face of a US dollar shock has been more homogeneous since the creation of the euro. What is striking, and perhaps more unexpected, is that this more homogeneous response is also now similar to that of one country, namely Germany. Germany's response has indeed hardly changed with the creation of the euro, since the depreciation of its real effective exchange rate further to a similar US dollar shock is estimated to have increased by barely 0.1 percentage points, to about $0.5 \%$.

Not only is the impact of a US dollar shock more similar across euro area countries contemporaneously, it is also more similar over time. Figure 9 reports the impulse response functions of the real effective exchange rate of four selected euro area countries (Germany, Italy, Greece and Ireland) further to a US dollar shock, both pre- and post-EMU, at horizons up to eight months. The figures show how synchronous the response has become across these countries after 1999. The initial depreciation of the real effective exchange rate dies out almost completely after roughly two months in all cases, and at a similar pace, which contrasts with the diverse responses that existed prior to EMU.

For the sake of comparison, Figures 10 and 11 report impulse response functions for selected major floaters (the United States, the United Kingdom, Japan and Switzerland) and selected new EU Member States (Poland, Hungary and Romania) as well as Iceland. Focusing first on the major floaters, the US dollar's reponse is clearly unchanged before and after EMU, which confirms that the shock remains similar and allows indeed to make relevant comparisons between the two estimation periods. For the other major currencies, there are clear differences in response patterns within each country and between the two estimation periods and, even more importantly, after 1999 across countries. This suggests that convergence towards Germany's response patterns was confined to euro area countries and unmatched in the rest of the world. As regards the new EU Member States, the advent of the euro seems to have also been a structural break as seen from the marked differences in respective responses' patterns before and after EMU. This perhaps reflects also the effect of the substantial increase in trade and financial integration between these countries and the euro area after the advent of the euro. Yet, post-EMU impulse response functions remain appreciably different from those of the euro area countries. This is 
even more so the case of Iceland, which has only started to embark on EU accession negotiations.

To assess more formally whether impulse response functions have changed statistically significantly, Table 4 reports measures of euclidian distance as described in (8) and (10). Specifically, the $\eta_{i}^{u s}$ statistics reported in the first column refer to the distance between the impulse response to a US dollar shock on country $i$ before and after EMU (distances significantly different from zero at the $10 \%$ critical value are highlighted in bold); the $\xi_{D E, j}^{u s}$ statistics reported in the second column refer to the distance between the impulse response to a US dollar shock on euro area member $j$ after EMU and Germany before EMU (distances which have become statistically significantly larger are highlighted in bold); and the $\xi_{i j}^{u s}$ statistics reported in the third column takes any of the euro area countries as a benchmark and therefore refers to the distance between the impulse response to a US dollar shock on euro area member $j$ and benchmark euro area member $i$ before EMU (the column reports the number of countries for which the distance has not become statistically significantly smaller after EMU).

The null hypothesis that the impact of a US dollar shock is the same before and after EMU is rejected for Finland, France, Ireland, Italy, Portugal and Greece, but not for the remaining euro area countries. Interestingly, $\eta_{i}^{u s}$ is smallest for Germany, suggesting that Germany's external competitiveness pattern of adjustment to US dollar shocks is the least affected by the creation of the euro. This is also true for Austria and the Netherlands, which used to manage their legacy currencies very tightly vis-à-vis the Deutsche Mark prior to EMU. Conversely, $\eta_{i}^{u s}$ is largest for Ireland, Italy and Greece (but not for Spain), three countries of the alleged "periphery" of the area.

The null hypothesis that the impact of a US dollar shock is the same after EMU as it was for Germany before EMU is rejected for none of the euro area countries. This confirms that the reponse of the real effective exchange rate of all euro are countries to a US dollar shock is now quite similar to that of Germany prior to EMU. In other words, the pattern of adjustment of euro area countries's external competitiveness in the face of such a global shock has converged after EMU to Germany's pattern before EMU. Put it again differently, their adjustment is not akin to the simple average of countries' patterns of adjustment before the euro, or to that of the country issuing the least credible of the legacy currencies, or even to something completely new, but to the pattern of adjustment of the economy that used to issue what is often regarded as one of the most credible of the legacy currencies. Last, but not least, the $\xi_{i j}^{u s}$ statistics suggests that the post-EMU responses of all euro area countries have become systematically closer to Germany's pre-EMU response. This again suggests that their corresponding pattern of adjustment in external competitiveness has converged to that of Germany. Conversely, there is evidence that 7 to 8 euro area countries' post-EMU responses have become more distant (i.e. diverged) from Portugal or Greece's pre-EMU responses. 


\subsection{Generalised impulse response function shocks}

We next turn to generalised shocks. As aforementioned, these cannot be interpreted as structural economic shocks (unlike risk shocks or dominant unit shocks), although they remain useful to understand the dynamics of global real effective exchange rates pre- and post- EMU. In constructing impulse response functions, we take into account restrictions relating to the dominance of the US dollar on the covariance matrix of the reduced-form residuals. By contrast with standard Cholesky decompositions of the covariance matrix, which relies on a recursive causal chain, the ordering of the variables is unimportant for GIRFs, which is a key advantage in our high dimensional case.

Figure 12 reports the contemporaneous impact (together with $90 \%$ bootstrapped bounds) of a onestandard deviation generalised shock to the residuals of selected country-equation, i.e. Canada, Japan and the United Kingdom. We decided to only present GIRF shocks to these countries' residuals as they are those issuing the most liquid currency in FX markets, after the US and the euro area. By and large, the results are qualitatively similar as those obtained with the US dollar shock. Before EMU, the contemporaneous response of euro area countries to a one-standard deviation generalised shock to the residuals of Canada, Japan and the United Kingdom's real effective exchange rate equations was somewhat diverse across countries (i.e. within a range of $-0.3 \%$ to $0.2 \%$ for the shock to the Canadian dollar; $-0.2 \%$ to $0 \%$ for the shock to the Japanese yen; $-0.4 \%$ to $0.4 \%$ for the shock to the Pound sterling). After EMU, similar shocks are associated with a more homogeneous contemporaneous reponse across euro area countries, namely a depreciation in the order of $-0.3 \%$ to $-0.1 \%$ for the shock to both the Japanese yen and the Pound sterling and an appreciation of some $0.2 \%$ to $0.5 \%$ for the shock to the Canadian dollar.

To assess more formally whether impulse response functions have changed statistically significantly, Table 5 reports measures of euclidian distance as described in (8) and (10), with broadly similar results as those obtained with the US dollar shock. The null hypothesis that the impact of a generalised shock to the three selected country-equations is the same before and after the EMU is again often rejected for countries at the "periphery" of the euro area (including for one of the three generalised shocks for Ireland and Portugal and for two of the three generalised shocks for Greece, Italy and Spain) with $\eta_{i}^{l}$ being smallest (or among the smallest) for Germany, suggesting again that Germany's real effective exchange rate is the least affected by the creation of the euro, at least as far as the impact of such generalised shocks is concerned. The null hypothesis that the impact of a generalised shock to the three selected country-equations is the same after EMU as it was for Germany before EMU is rejected for none of the euro area countries. This confirms again that the reponse of the real effective exchange rate of all euro are countries to such shocks is now more similar to that of Germany prior to EMU or, differently put, that their pattern of adjustment is now akin to that of the country issuing what is often regarded as one of the most credible of the legacy currencies. Last, but not least, the $\xi_{i j}^{l}$ statistics 
confirms that the post-EMU responses of all euro area countries have become systematically closer to Germany's pre-EMU response.

\subsection{Risk aversion shocks}

To identify risk aversion shocks, we draw 2,000 candidate shocks that satisfy the required signs and replicate this exercise with 200 boostrap replications to address the estimation uncertainty. We do this for each of our decade-long estimation periods. Figure 13 reports the median and quantiles of the successful draws.

There is evidence that euro area legacy currencies assumed a safe haven role before EMU, particularly those of the countries belonging to the alleged "core" of the future area. In line with this, the impact of a shock to risk aversion generally triggered an appreciation of these euro area legacy currencies. Such a shock to risk aversion ${ }^{19}$ was associated with a $0.5 \%$ contemporaneous appreciation of the Deutsche Mark. Other currencies from future euro area members appreciated in tandem -including that of Austria, Belgium, Finland, France, Ireland, Luxembourg and the Netherlands- within a range of about $0.2 \%$ to $0.5 \%$. Currencies of some of the countries at the alleged "periphery" of the future area did not have such a safe haven role, however. In particular, Italy, Spain and Portugal's real effective exchange rates tended to depreciate (although the impact was insignificantly different from zero for Italy), and that of Greece was clearly unaffected.

The picture after EMU is, again, completely different. Almost all euro area countries' real effective exchange rates now respond more similarly to a shock to risk aversion. According to the estimates, further to a shock to risk aversion ${ }^{20}$ the real effective exchange rate of most euro area countries tend to depreciate contemporaneously, within a range of $-0.5 \%$ to $-0.3 \%$. Two exceptions are Finland and Portugal's exchange rates, which remain unaffected by the shock. In other words, the response of the real effective exchange rate of most euro are countries to global shocks to risk aversion is now more similar to that of Spain or Italy prior to EMU. Importantly, and similarly as for a global US dollar shock, euro area countries' real effective exchange rates depreciate when the US dollar appreciates further to a post-EMU shock to global risk aversion. In our interpretation, this might reflect the fact that the euro has become the globally most relevant alternative to the US dollar as an international currency, with a liquidity unmatched by any of the legacy currencies, and hence the main counterpart to US dollar movements. ${ }^{21}$ Moreover, one of the most noteworthy changes is Germany's response pattern, from appreciation before EMU -when the Deutsche Mark had a safe haven status- to depreciation after EMU- along with all other euro area countries.

\footnotetext{
${ }^{19}$ Corresponding to an appreciation of the US dollar, Japanese yen and Swiss franc of $0.5 \%, 1.5 \%$ and $1.2 \%$, respectively; a depreciation of the Korean won and Polish zloty of $-3.1 \%$ and $-3.0 \%$, respectively; and an increase in the VIX of $10 \%$.

${ }^{20}$ Corresponding to an appreciation of the US dollar, Japanese yen and Swiss franc of $1.2 \%, 2.2 \%$ and $1.2 \%$, respectively; a depreciation of the Korean won and Polish zloty of $-2.4 \%$ and $-2.2 \%$, respectively; and an increase in the VIX of $20 \%$.

${ }^{21}$ This seemed notably the case in the $2007 / 9$ crisis, in particular at times of heightened uncertainty and flight to the safety and liquidity of US dollar assets (see e.g. McCauley and McGuire (2009)).
} 
Figures 14, 15 and 16 report the impulse response functions to a risk aversion shock for selected euro area countries, other major floaters, New EU Member States and Iceland, respectively, as in Section 6.1. Not surprisingly, the US dollar, Japanese yen and Swiss franc appreciate further to a risk aversion shock (with the impact of the shock vanishing completely after about two to four months), while the Polish zloty depreciates (with the impact of the shock vanishing completely after about two to five months), in line with the signs chosen for our identification scheme.

As a robustness check, we have also re-estimated the post-EMU system with a shorter sample period that excludes the 2007/9 global financial crisis (with the sample ending in June 2007) to abstract from possible effects arising from the period of exceptional market volatility that prevailed during these two years. Interestingly, the results for the risk shock are qualitatively similar, albeit with larger quantiles ranges, which suggests that our benchmark results were not driven by the global financial crisis.

As aforementioned, we do not have here a unique shock that statisfies the restricted signs but many. Hence, many different impulse response candidates (not only one) could be used to calculate euclidian distance measures. We have followed the literature by reporting median and quantiles of the impulse responses obtained through bootstrap replications. It should be highlighted, however, that the median itself is not an impulse response function per se (and generally does not belong to the space of impulse responses). For this reason measures of euclidian distance are not calculated for this particular type of shock.

\section{Conclusion}

The aim of this paper was to assess whether the creation of the euro changed the way global turbulences affect euro area and other economies, focusing on the adjustment of competitiveness in the face of global economic shocks. To this aim, it has drawn from a newly developed econometric technique, applying infinite VAR theory featuring a dominant unit to a large set of over 60 countries' real effective exchange rates. We have estimated two high dimensional VARs -one before and one after EMU- and compared them by investigating the spatio-temporal transmission of three types of shocks: (global) US dollar shocks, (non-identified) generalised shocks and (global) risk aversion shocks. The estimated systems successfully pass a range of specification tests with regard to stability, economic meaningfulness of the coefficients, weak exogeneity of the dominant unit, residual serial correlation and structural breaks. They are also robust to controlling for one-off exceptional events of unusually large exchange rate movements, such as devaluations or realignments in the European Exchange Rate Mechanism, as well as to a shorter estimation period, and notably to the exclusion of the $2007 / 9$ global financial crisis which allows to abstract from possible effects arising from the period of exceptional market volatility that prevailed at the time.

The creation of the euro has significantly changed the way global turbulence affect euro area and 
other economies. We find that the pattern of responses depends crucially on the nature of global shocks. One of the paper's key result is that the response of euro area countries has become more similar to that of Germany, i.e. the economy that issued the anchor legacy currency in Europe prior to EMU, when it come to US dollar shocks or different generalised shocks considered in the paper. By contrast, when considering shocks to global risk aversion, the response of euro area countries' real effective exchange rates has become more distant from that of Germany prior to EMU and closer to that of countries such as Italy, Portugal or Spain prior to EMU.

Importantly, in the case of both types of global shocks, euro area countries' real effective exchange rates depreciate when the US dollar appreciates after EMU. In our interpretation, this might reflect the fact that the euro has become the globally most relevant alternative to the US dollar as an international currency, with a liquidity unmatched by any of the legacy currencies, and hence the main counterpart to US dollar movements. One of the most noteworthy changes is Germany's response pattern to global risk aversion shocks, from appreciation before EMU - when the Deutsche Mark had a safe haven statusto depreciation after EMU- along with all other euro area countries.

An implication of the results could be that euro area economies might not necessarily be subject to marked appreciation pressures in periods of heightened global risk aversion, an undeniable benefit for Germany according to some observers. ${ }^{22}$ Our results give empirical support to this claim, at least for the first ten years of EMU. But if an adverse US dollar shock were to occur down the line, rather than a shock to global risk aversion, such as a massive loss of confidence in the US currency (due to e.g. the US's high fiscal and external imbalances), the real effective exchange rates of euro area countries would then be subject to marked appreciation pressures, as suggested by our results.

Looking ahead, the findings presented in the paper also suggest that the dissimilarities in external competitiveness among euro area countries over the last decade, which are at the core of today's debate on the future of the euro area, is unlikely to have been caused by the impact of global shocks considered here. Future research could therefore look into country-specific domestic shocks as the main source of divergence in external competitiveness across the euro area. This calls, for instance, for further examination of the response of real effective exchange rates in the first decade of EMU to shocks relating to domestic wage setting and bargaining, domestic price flexibility and domestic non-price competitiveness. Identifying the geographical origin of non-dominant shocks in large VAR systems is for this reason a topic that would deserve particular attention in future research.

\footnotetext{
${ }^{22}$ Such a view is most candidly expressed by a column of M. Wolf, the Financial Times' Chief Economics commentator, written in late-2010 (Wolf (2010)): "The euro has also shielded the German economy from what would have been still bigger shocks: imagine what would have happened, in the absence of the euro. The exchange rate of the D-Mark would have exploded upwards, as currency crises savaged the European economy, as happened in the 1990s. In peripheral Europe, currency depreciations would have been at least as big as, if not bigger than, sterling's. The absence of such shocks has greatly enhanced the prospects for the German recovery. The creation of the eurozone was, for this reason alone, much more than a favour Germany did for its partners. It was also a big economic (not to mention political) gain for Germany. German industrialists are clear on this, as is the government".
} 
Table 1: Standard deviation and total cumulated change of the euro area countries' real effective exchange rate changes (pre- and post-EMU)

\begin{tabular}{lcccc}
\hline \hline & \multicolumn{2}{c}{ Standard deviation } & \multicolumn{2}{c}{ Cumulated change } \\
\cline { 2 - 5 } & $1988-1999$ & $1999-2009$ & $1988-1999$ & $1999-2009$ \\
\hline Austria & $0.80 \%$ & $0.69 \%$ & $4.8 \%$ & $6.4 \%$ \\
Belgium & $0.89 \%$ & $0.74 \%$ & $-0.3 \%$ & $12.3 \%$ \\
Finland & $1.68 \%$ & $1.57 \%$ & $-17.6 \%$ & $7.6 \%$ \\
France & $0.81 \%$ & $0.77 \%$ & $-5.1 \%$ & $8.1 \%$ \\
Germany & $1.71 \%$ & $0.93 \%$ & $-18.4 \%$ & $6.4 \%$ \\
Germany (excl. 01/91) & $0.99 \%$ & - & - & - \\
Ireland & $1.67 \%$ & $1.74 \%$ & $-9.5 \%$ & $30.4 \%$ \\
Italy & $1.67 \%$ & $0.82 \%$ & $-9.5 \%$ & $13.5 \%$ \\
Luxembourg & $0.89 \%$ & $0.49 \%$ & $5.5 \%$ & $11.3 \%$ \\
Netherlands & $0.86 \%$ & $0.83 \%$ & $-2.8 \%$ & $14.0 \%$ \\
Portugal & $0.89 \%$ & $0.72 \%$ & $27.2 \%$ & $13.3 \%$ \\
Spain & $1.17 \%$ & $0.57 \%$ & $-3.9 \%$ & $19.9 \%$ \\
Greece & $1.09 \%$ & $0.73 \%$ & $23.4 \%$ & $19.9 \%$ \\
\hline \hline
\end{tabular}

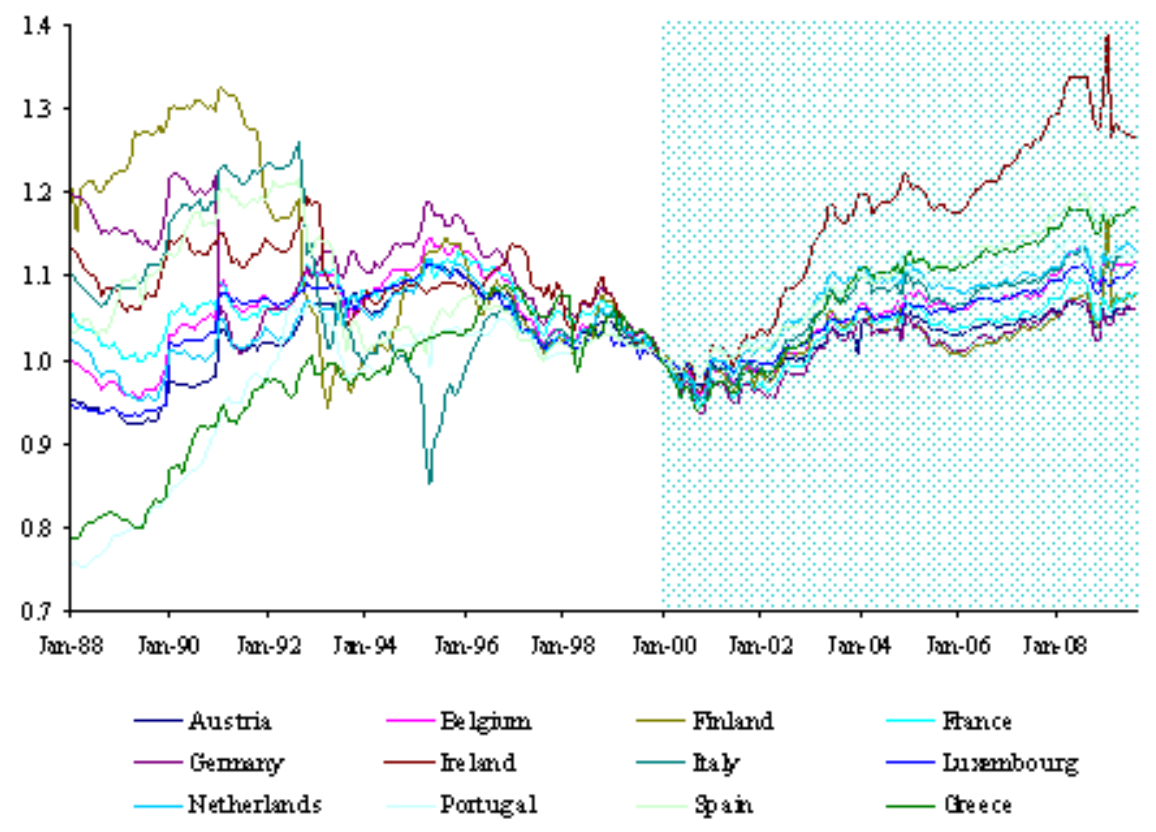

Figure 1: Real effective exchange rates of the euro area countries (in log levels) 

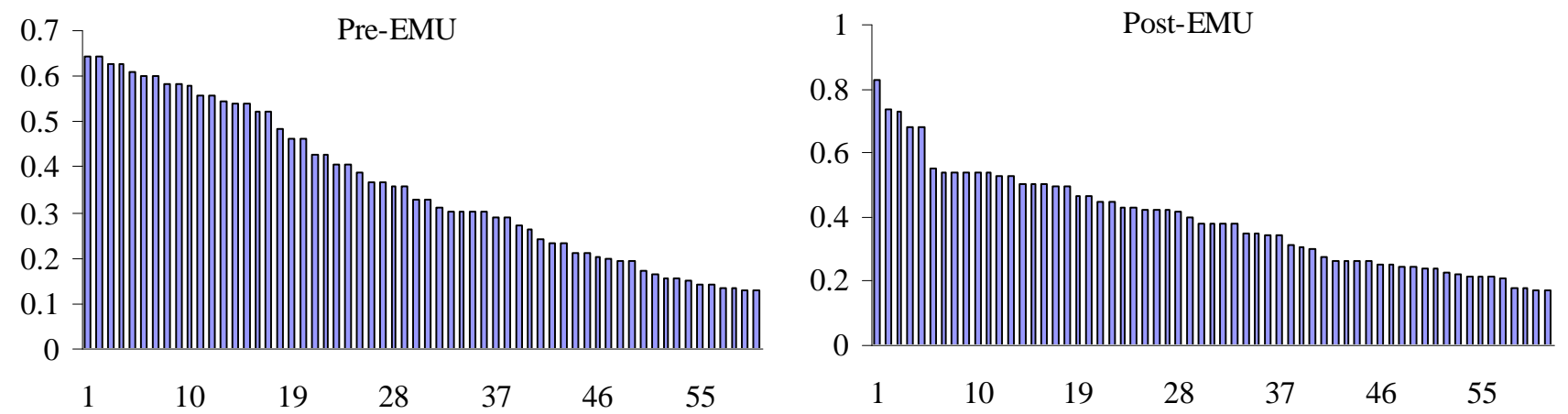

Figure 2: Absolute value of the largest 60 eigenvalues of the estimated IVAR system's respective companion matrix (ranked in descending order)

Table 2: Overview of the statistical significance of the variables ( $5 \%$ level)

\begin{tabular}{rcccc}
\hline \hline & $\begin{array}{c}\text { Pre-EMU IVAR system } \\
\text { No. of } \\
\end{array}$ & $\begin{array}{c}\text { Post-EMU IVAR system } \\
\text { Share in total } \\
\text { signicant coef. } \\
\text { no. of coef. }\end{array}$ & $\begin{array}{c}\text { No. of } \\
\text { significant coef. }\end{array}$ & $\begin{array}{c}\text { Share in total } \\
\text { no. of coef. }\end{array}$ \\
\hline Variables capturing possible strong cross-section dependence & \\
\hline US dollar & 37 & $\mathbf{6 2 \%}$ & 48 & $\mathbf{8 0 \%}$ \\
(lagged) US dollar & 19 & $\mathbf{2 8 \%}$ & 11 & $\mathbf{1 8 \%}$ \\
C.S. average & 13 & $\mathbf{2 2 \%}$ & 33 & $\mathbf{5 5 \%}$ \\
(lagged) C.S. average & 7 & $\mathbf{1 1 \%}$ & 9 & $\mathbf{1 5 \%}$ \\
\hline Variables capturing possible weak cross-section dependence & & \\
\hline Lagged spatial effects: & & & $\mathbf{8 \%}$ \\
trade & 7 & $\mathbf{1 1 \%}$ & 5 & $\mathbf{7 \%}$ \\
(equity) financial & 7 & $\mathbf{1 6 \%}$ & 3 & $\mathbf{9 \%}$ \\
(debt) financial & 4 & $\mathbf{9 \%}$ & 4 & $\mathbf{5 8 \%}$ \\
Own lags & 40 & $\mathbf{5 5 \%}$ & 9 & $\mathbf{1 3 \%}$ \\
Other neighbours & 14 & $\mathbf{2 0 \%}$ &
\end{tabular}

Notes: C.S. average $=$ country-specific average of foreign variables. 

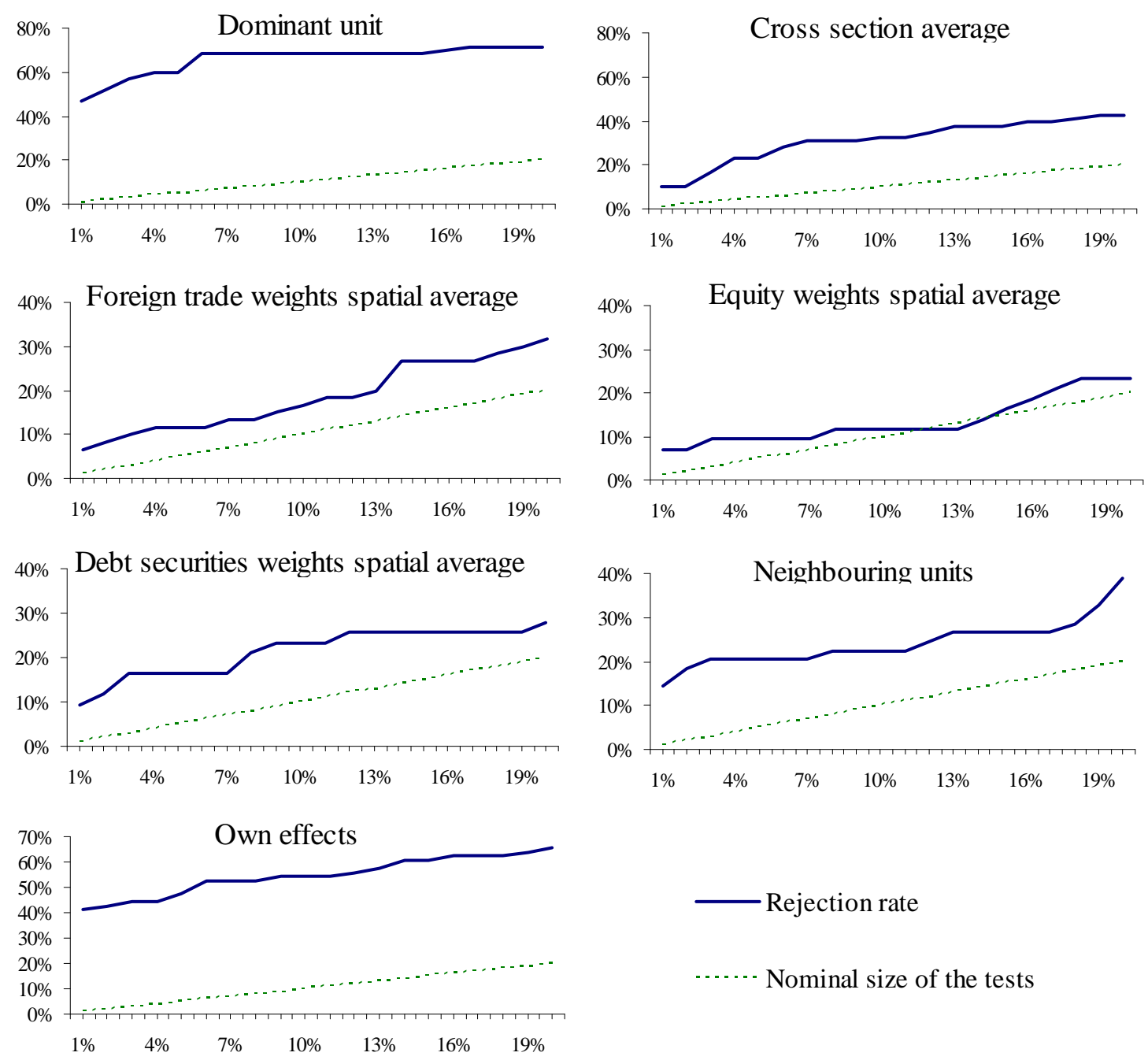

...... Nominal size of the tests

Figure 3: Pre-EMU F-test results - Rejection rate of the joint null hypothesis of statistical insignificance of lagged and contemporaneous variable values and size of the test

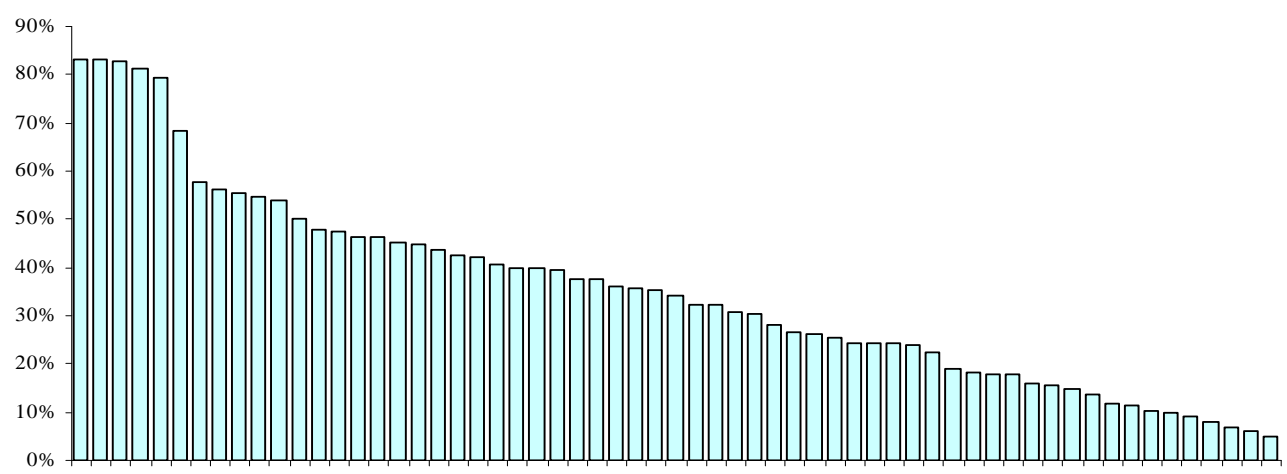

Figure 4: $\bar{R}^{2}$ of the individual country equations (post-EMU IVAR) 

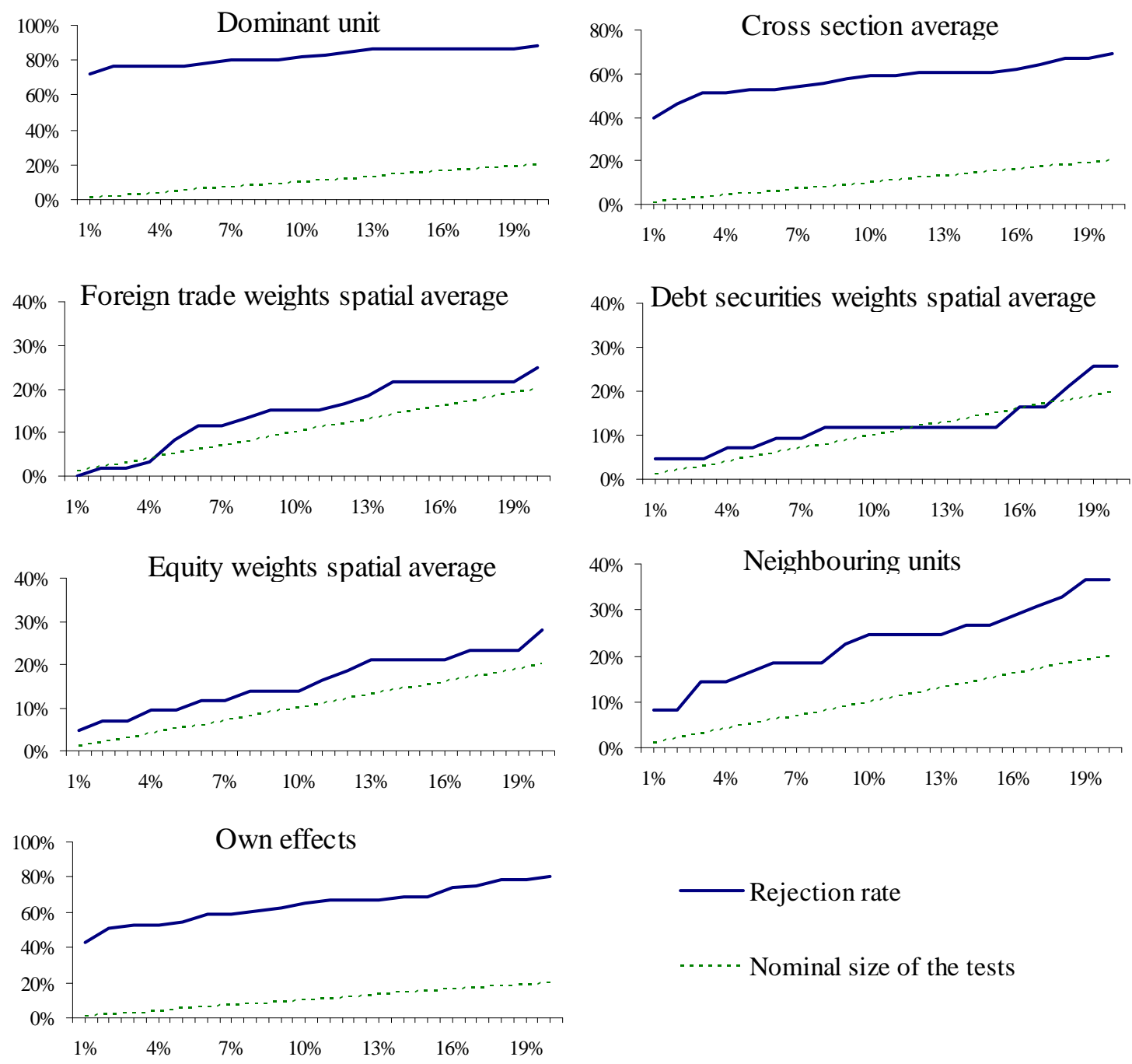

Figure 5: Post-EMU F-test results - Rejection rate of the joint null hypothesis of statistical insignificance of lagged and contemporaneous variable values and size of the test

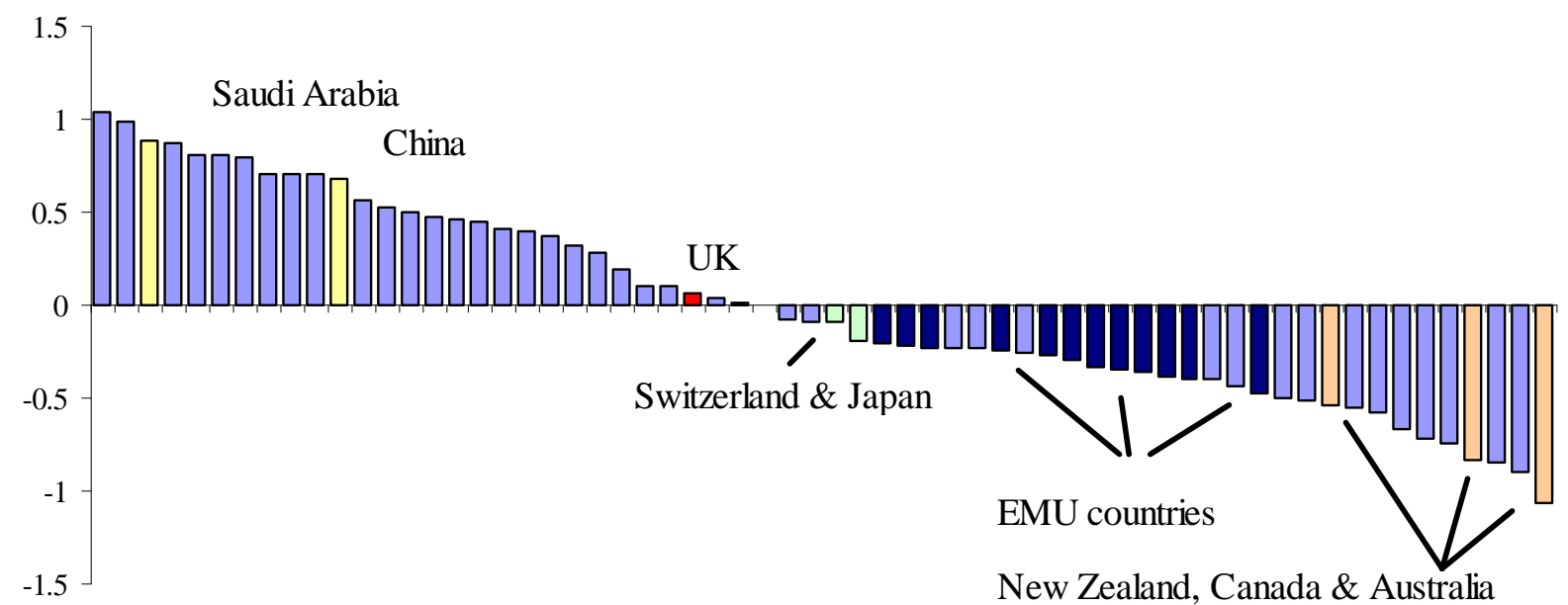

Figure 6: Elasticity of the 61 dependant real effective exchange rates with respect to contemporaneous US dollar changes (post-EMU) 
Table 3: Overview of structural break tests

\begin{tabular}{rrrrr}
\hline \hline & \multicolumn{2}{c}{ Pre-EMU } & \multicolumn{2}{c}{ Post-EMU } \\
Tests & Number & $\begin{array}{r}\text { percentage } \\
\text { (out of } 62)\end{array}$ & Number & $\begin{array}{r}\text { percentage } \\
\text { (out of } 62)\end{array}$ \\
\hline$P K_{\text {sup }}$ & 5 & $\mathbf{8 \%}$ & 3 & $\mathbf{5 \%}$ \\
$P K_{m s q}$ & 5 & $\mathbf{8 \%}$ & 4 & $\mathbf{6 \%}$ \\
$R$ & 7 & $\mathbf{1 1 \%}$ & 16 & $\mathbf{2 6 \%}$ \\
$r-R$ & 9 & $\mathbf{1 5 \%}$ & 9 & $\mathbf{1 5 \%}$ \\
$Q L R$ & 17 & $\mathbf{2 7 \%}$ & 12 & $\mathbf{1 9 \%}$ \\
$r-Q L R$ & 6 & $\mathbf{1 0 \%}$ & 1 & $\mathbf{2 \%}$ \\
$M W$ & 16 & $\mathbf{2 6 \%}$ & 12 & $\mathbf{1 9 \%}$ \\
$r-M W$ & 5 & $\mathbf{8 \%}$ & 6 & $\mathbf{1 0 \%}$ \\
$A P W$ & 17 & $\mathbf{2 7 \%}$ & 11 & $\mathbf{1 8 \%}$ \\
$r-A P W$ & 6 & $\mathbf{1 0 \%}$ & 1 & $\mathbf{2 \%}$ \\
\hline \hline
\end{tabular}

Notes: The table shows the number (percentage) of rejections of the null of no structural break in each of the 62 country-specific equations for the two IVAR models at the $5 \%$ level of confidence. Various structural break tests are considered here: $P K_{s u p}$ and $P K_{m s q}$, refer to tests based on the cumulative sums of OLS residuals; $R$ is the Nyblom test for time-varying parameters; $Q L R$, $M W$ and $A P W$ are the sequential Wald statistics for a single break at an unknown point in time. The prefix ' $r$ ' denotes heteroskedasticity-robust versions of the latter tests. Critical values are computed under the null of no structural break and are calculated by bootstrap replications.

Table 4: Measures of euclidian distance between impulse response functions

\begin{tabular}{rccr}
\hline \hline & & & \multicolumn{2}{c}{ No. of } \\
Country $i$ & $\eta_{i}^{U S}$ & $\xi_{D E, j}^{U S}$ & rejections for $\xi_{i j}^{U S}$ \\
\hline Austria & $0.17(0.24)$ & $0.19(0.59)$ & 4 \\
Belgium & $0.23(0.28)$ & $0.14(0.52)$ & 3 \\
Finland & $\mathbf{0 . 5 8 ( \mathbf { 0 . 4 6 } )}$ & $0.44(0.60)$ & 2 \\
France & $\mathbf{0 . 2 9 ( \mathbf { 0 . 2 5 } )}$ & $0.14(0.51)$ & 3 \\
Germany & $0.15(0.48)$ & $0.15(0.48)$ & 0 \\
Ireland & $\mathbf{0 . 6 9 ( \mathbf { 0 . 3 1 } )}$ & $0.53(0.56)$ & 3 \\
Italy & $\mathbf{0 . 6 9 ( \mathbf { 0 . 5 0 } )}$ & $0.14(0.94)$ & 4 \\
Luxembourg & $0.38(0.41)$ & $0.16(0.82)$ & 4 \\
Netherlands & $0.20(0.27)$ & $0.13(0.52)$ & 3 \\
Portugal & $\mathbf{0 . 2 8} \mathbf{( 0 . 2 4 )}$ & $0.25(0.68)$ & 1 \\
Spain & $0.18(0.33)$ & $0.18(0.41)$ & 8 \\
Greece & $\mathbf{0 . 4 4}(\mathbf{0 . 3 1})$ & $0.10(0.77)$ & 7 \\
\hline \hline
\end{tabular}

Notes: $\eta_{i}^{U S}$ is the euclidean distance between the impulse responses to a US dollar shock for euro area country $i$ before and after EMU; see (8). The $90 \%$ critical values reported in parentheses for hypothesis (9) that the distance is zero are computed by bootstrap replications under the null of no structural break; $\xi_{D E, j}^{U S}$ is the euclidian distance between the impulse responses to a US dollar shock for euro area country $j$ after EMU and that for Germany before EMU; see (10). The 90\% critical values reported in parentheses are calculated by bootstrap replications for the null hypothesis (11) that the distance is not larger; $\xi_{i j}^{U S}$ is the euclidian distance between the impulse responses to a US dollar shock for euro area country $j$ after EMU and euro area member $i$ before EMU; the column reports the number of countries for which the null that the distance is smaller is rejected. 

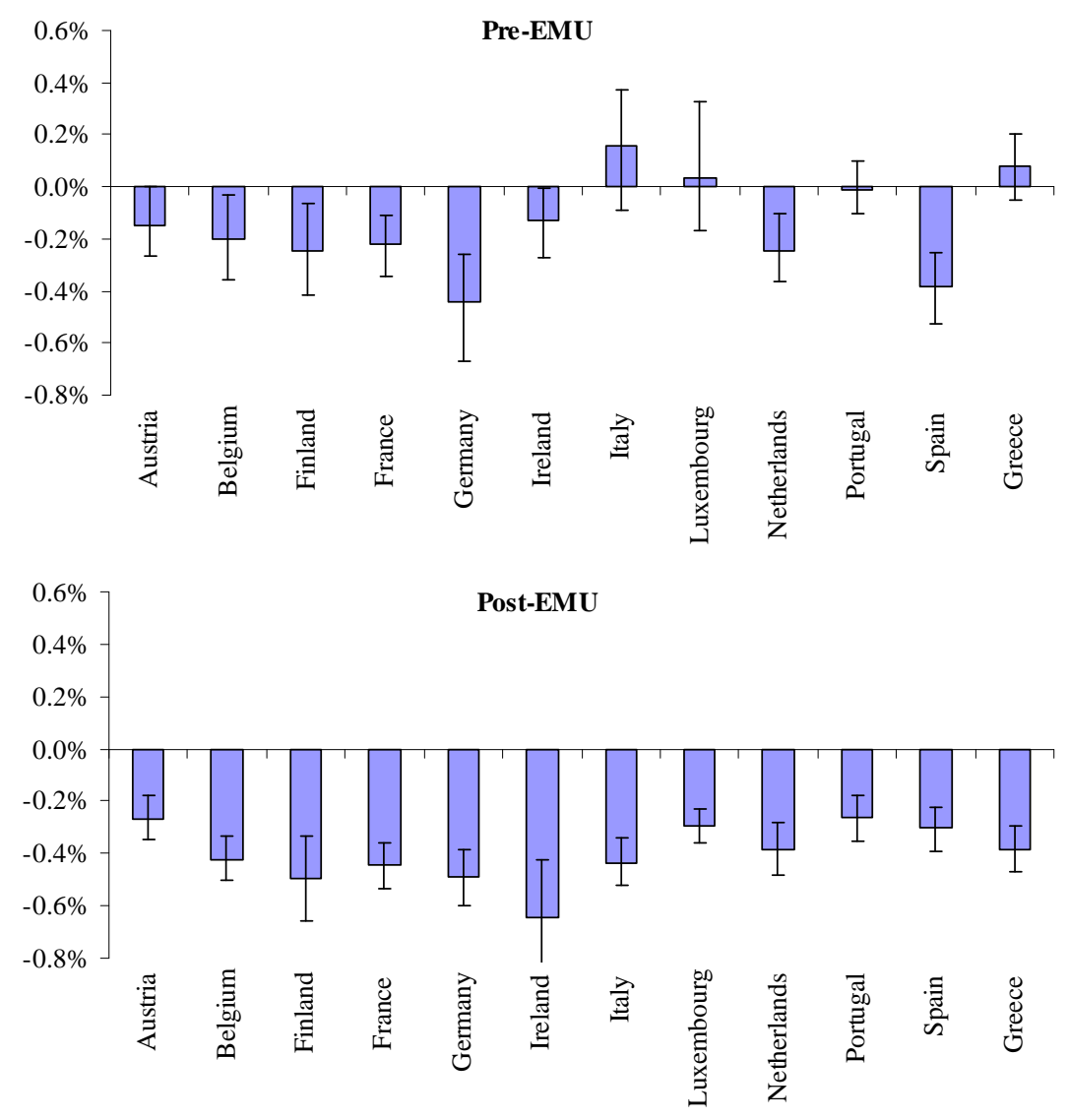

Figure 7: Contemporaneous impact of a one-standard deviation generalised shock to the dominant unit (US/US dollar) on the euro area countries' real effective exchange rate

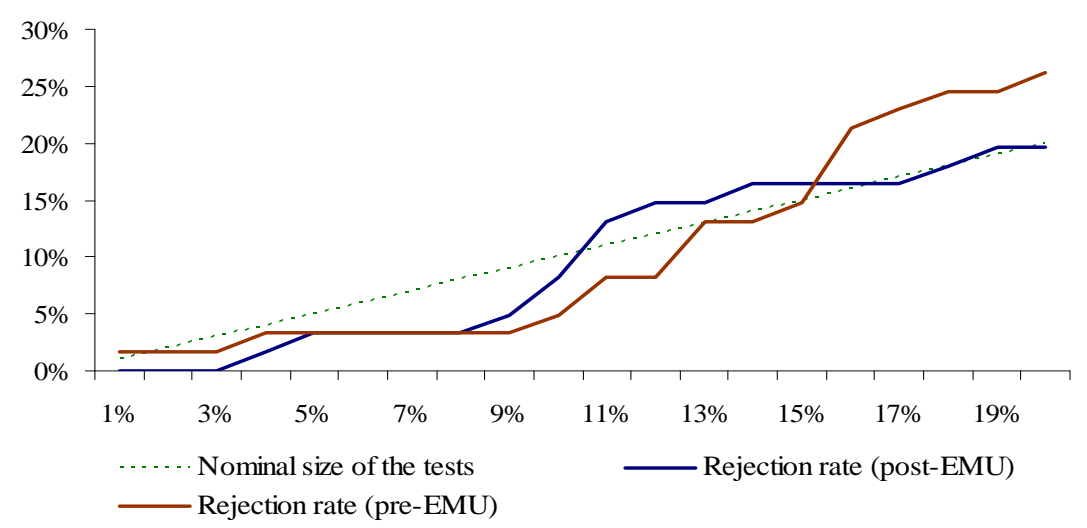

Figure 8: Rejection rates from Wu-Hausman weak exogeneity tests (pre- and post-EMU). 
Pre-EMU

Post-EMU

Germany
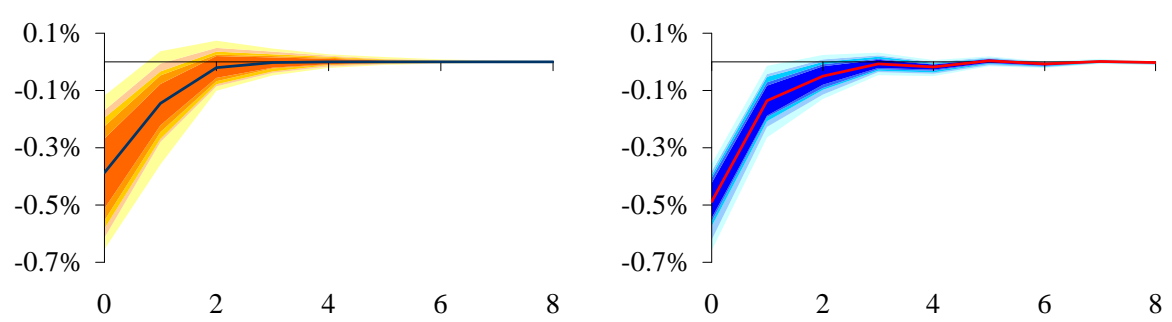

Italy
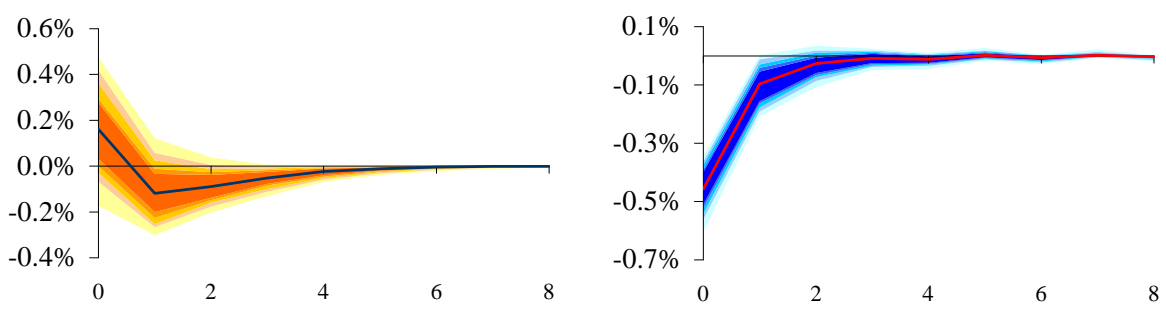

Greece
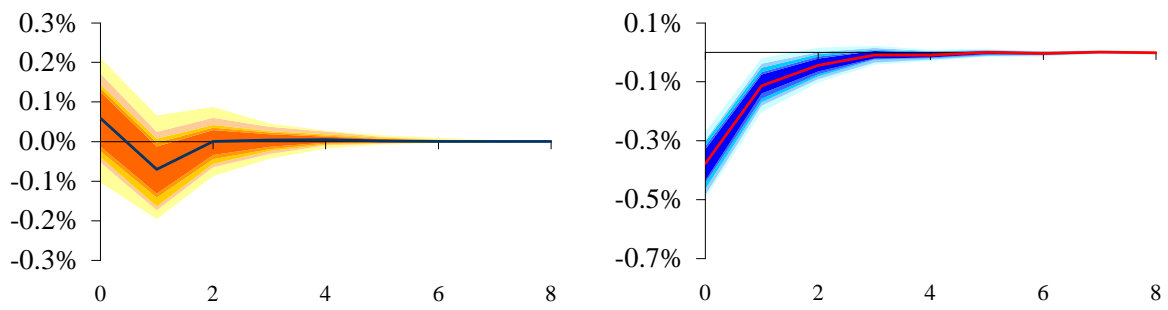

Ireland
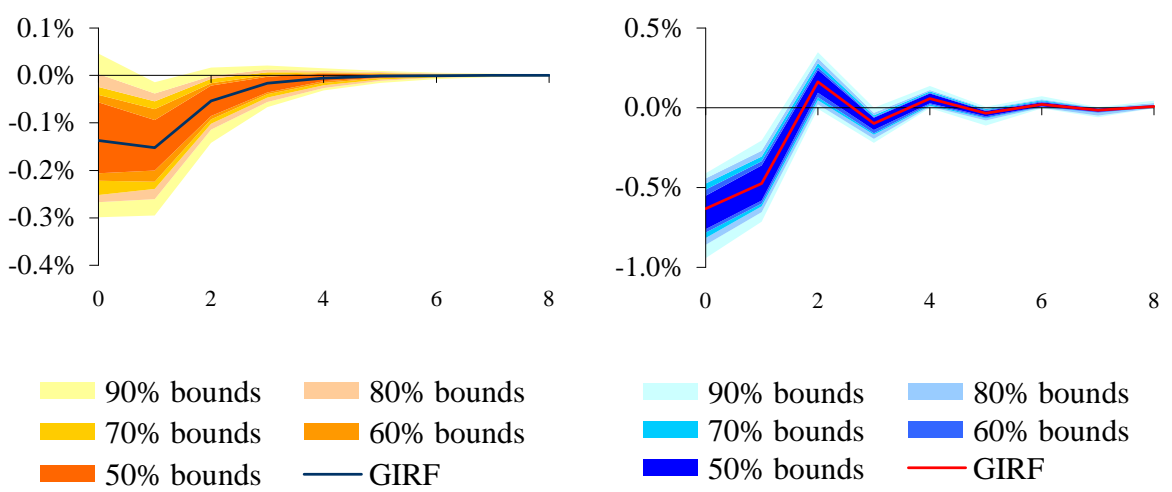

Figure 9: Impulse response function to a one-standard deviation generalised shock to the dominant unit (US/US dollar) for selected euro area countries' real effective exchange rate 
Pre-EMU

Post-EMU

United States
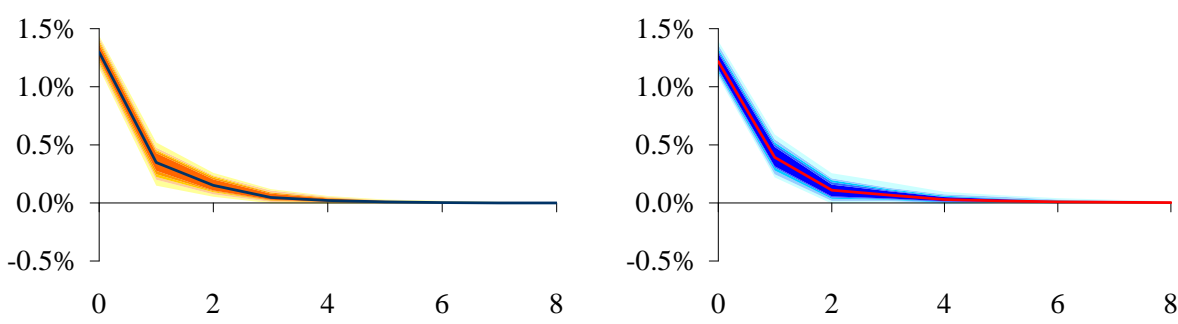

United Kingdom
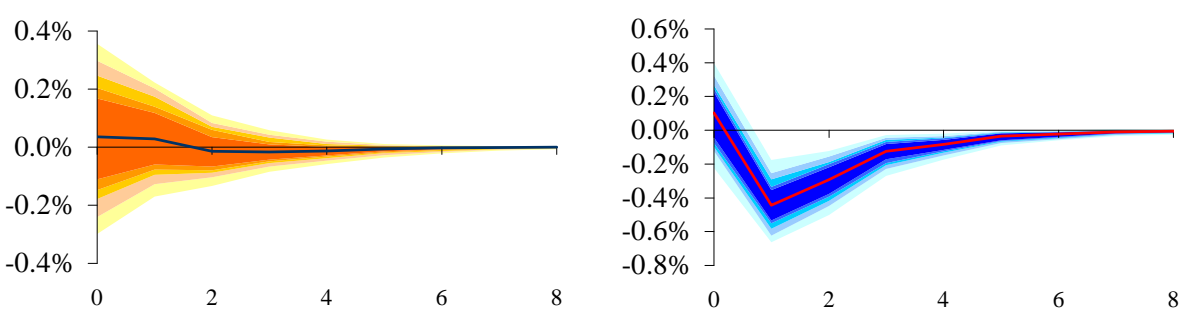

Japan

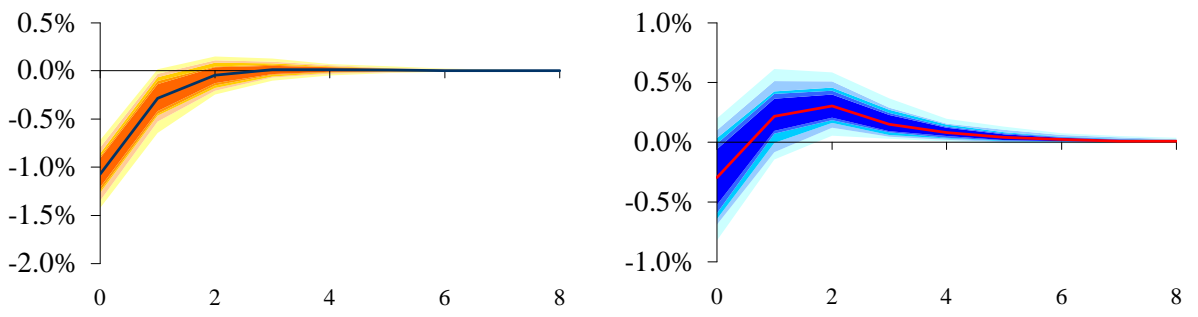

Switzerland
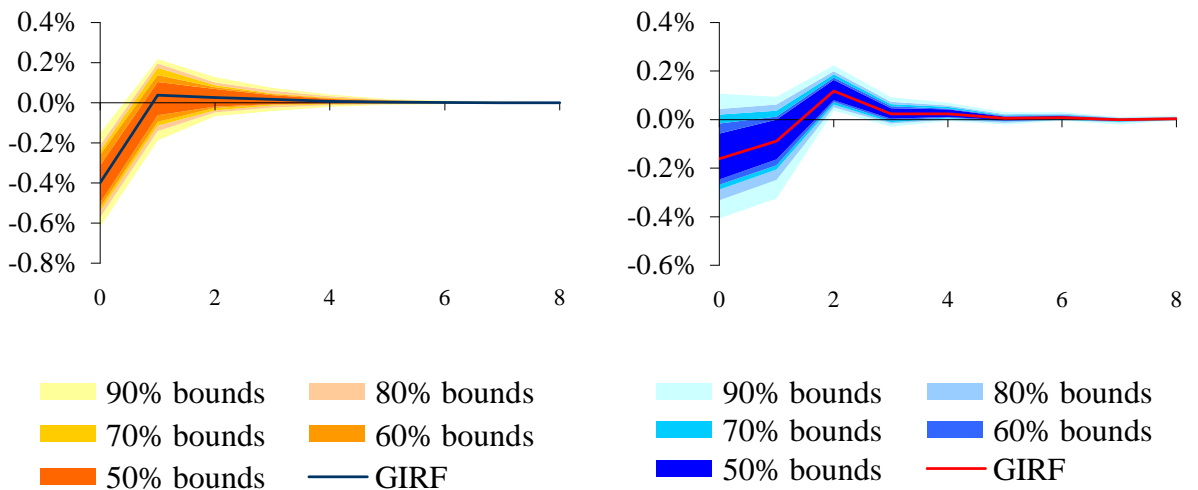

Figure 10: Impulse response function to a one-standard deviation generalised shock to the dominant unit (US/US dollar) for selected major floaters' real effective exchange rate 
Pre-EMU

Post-EMU

Hungary

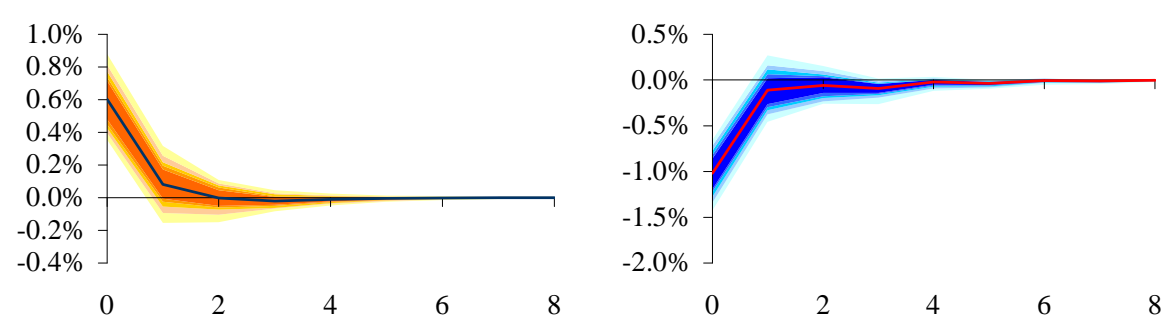

Poland

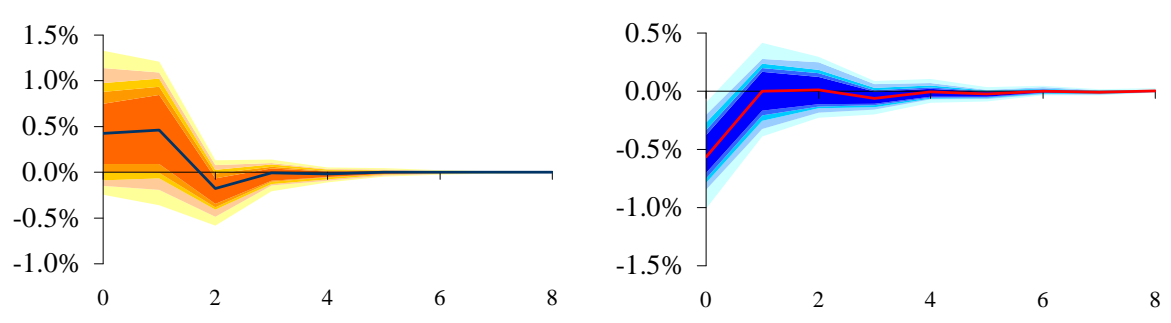

Romania
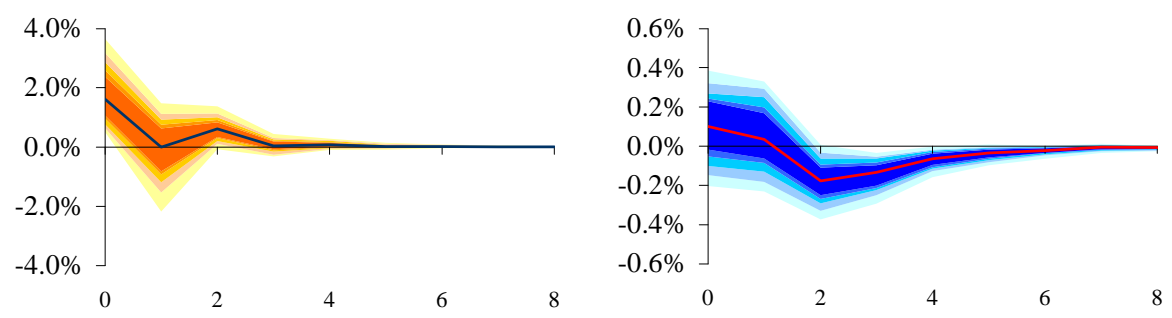

Iceland
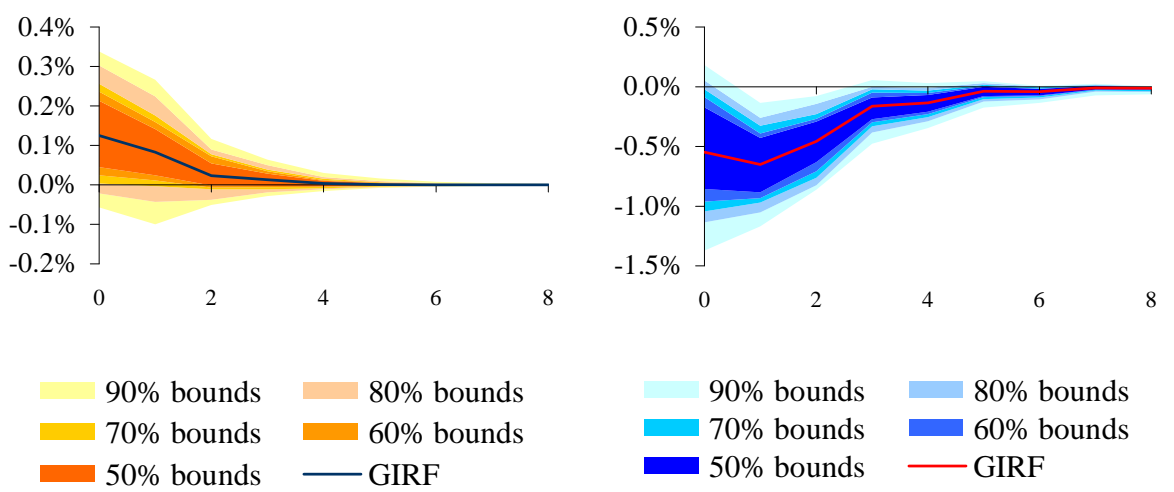

Figure 11: Impulse response function to a one-standard deviation generalised shock to the dominant unit (US/US dollar) for selected new EU Member States and Iceland's real effective exchange rate 

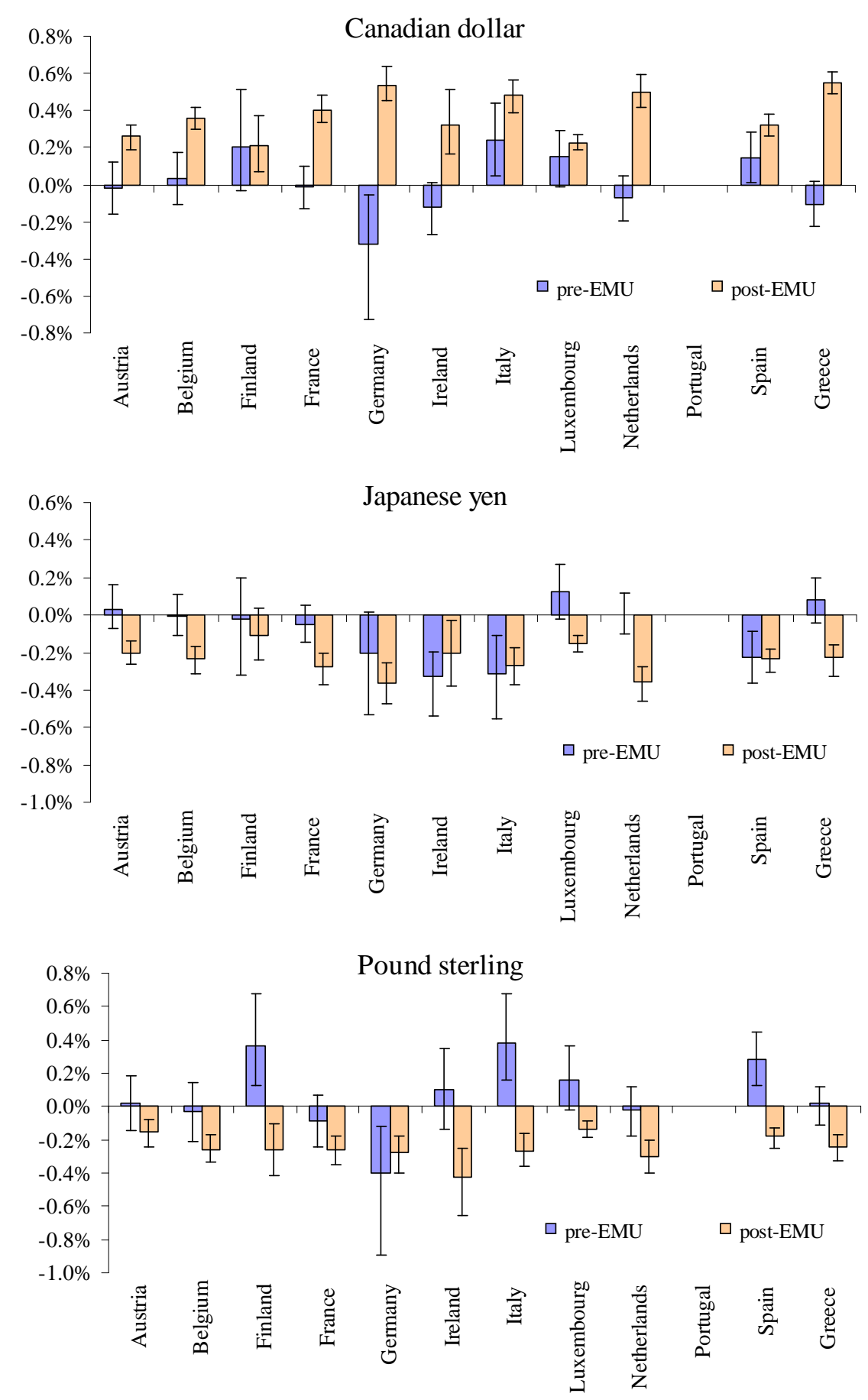

Figure 12: Contemporaneous impact of a one-standard deviation generalised shock to the major floating currencies (other than the US dollar or the euro) on euro area countries' real effective exchange rate 

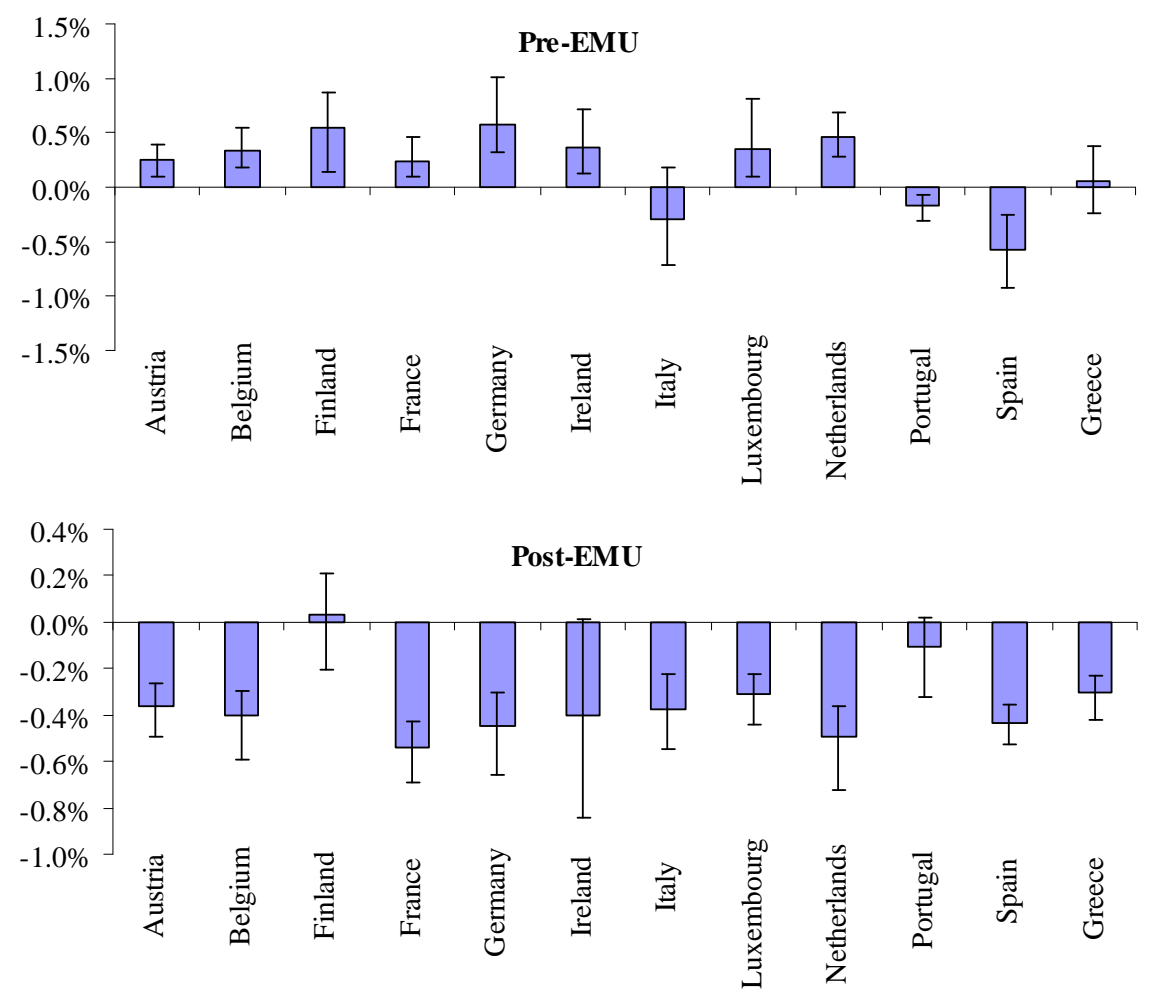

Figure 13: Contemporaneous impact of a shock to risk aversion (median and $90 \%$ quantile range) on euro area countries' real effective exchange rate 
Pre-EMU

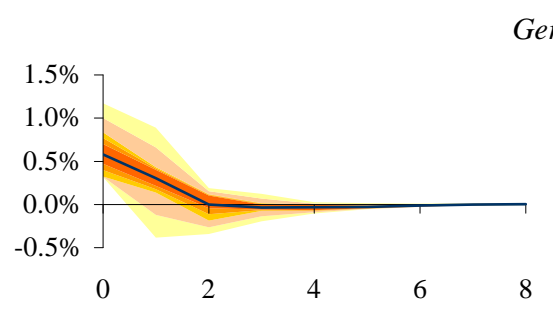

Post-EMU

Germany

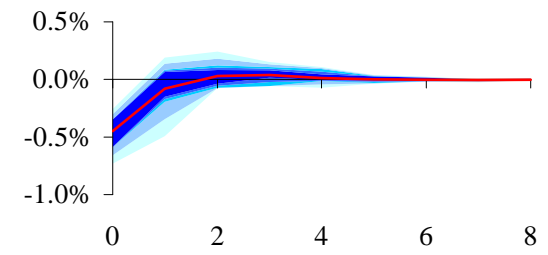

Italy
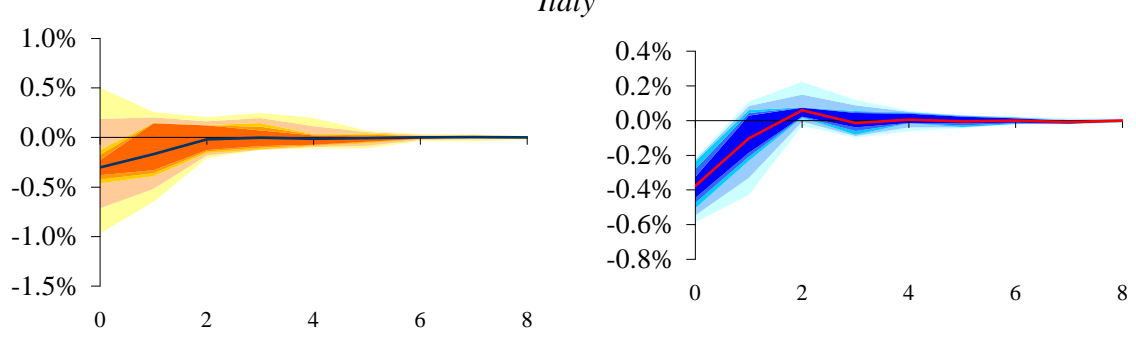

Greece

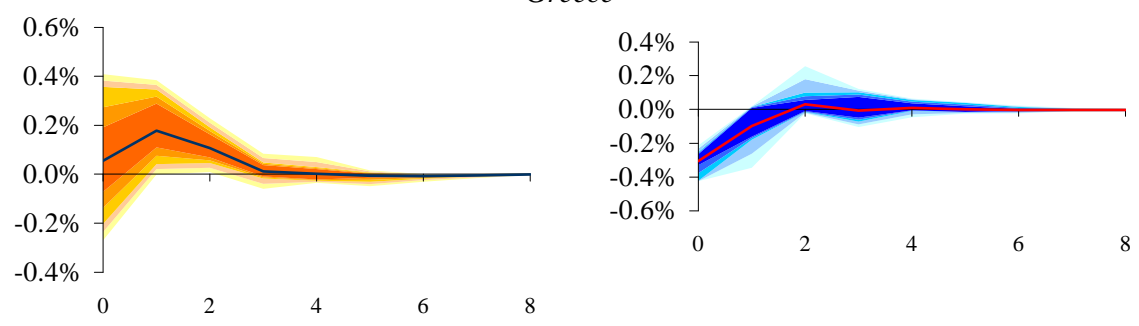

Ireland
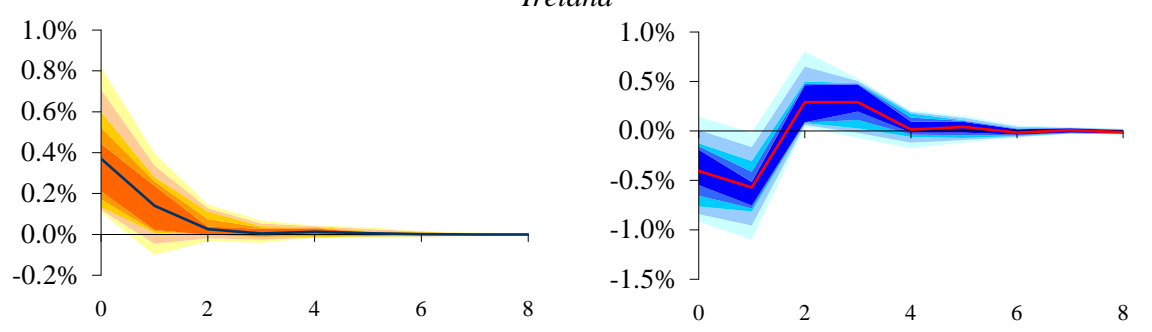

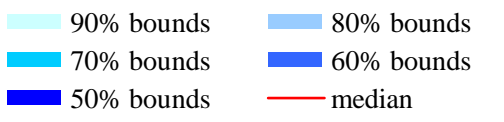

Figure 14: Impulse response function to a shock to risk aversion (median and up to $90 \%$ quantile ranges) on selected euro area countries' real effective exchange rate 
Pre-EMU

Post-EMU
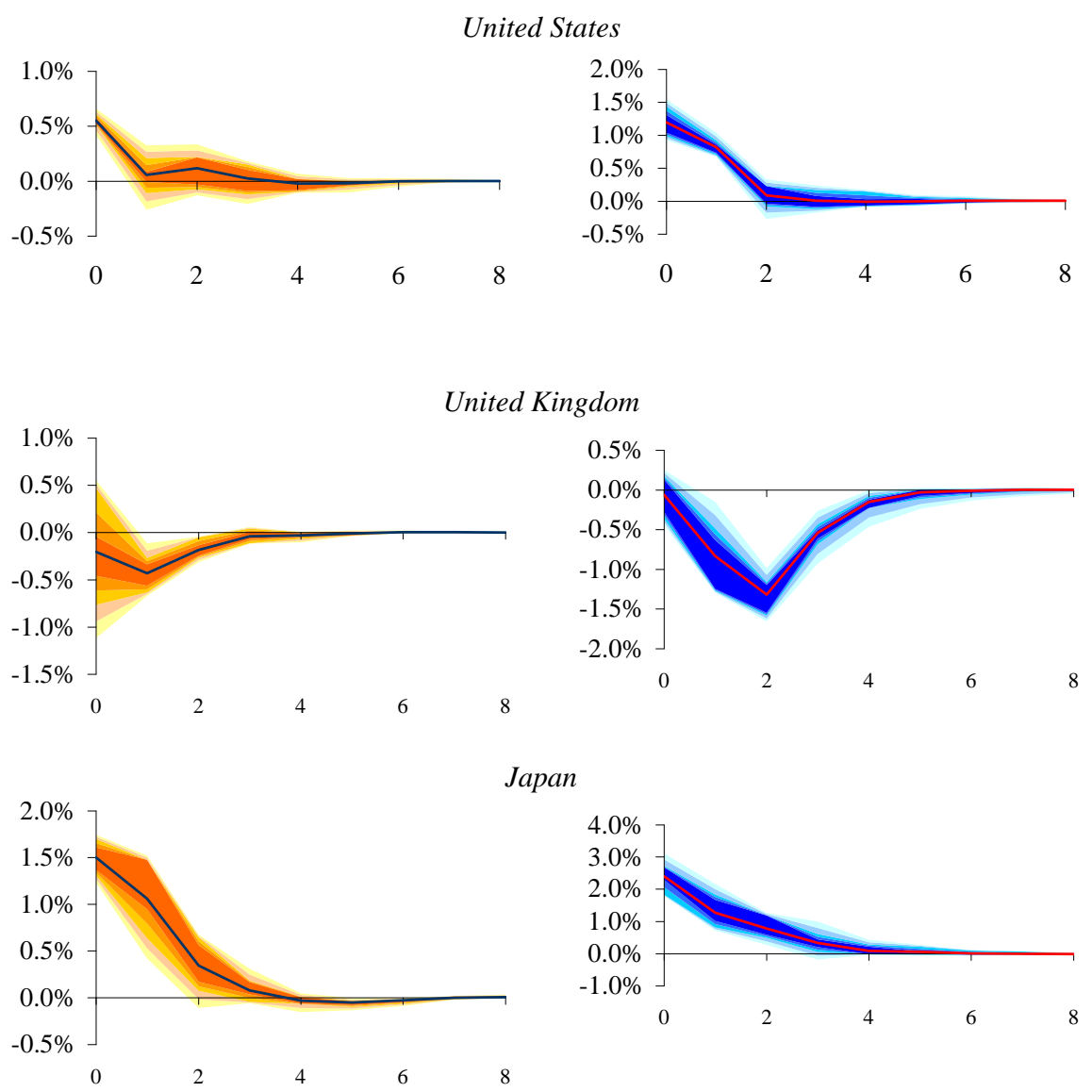

Switzerland
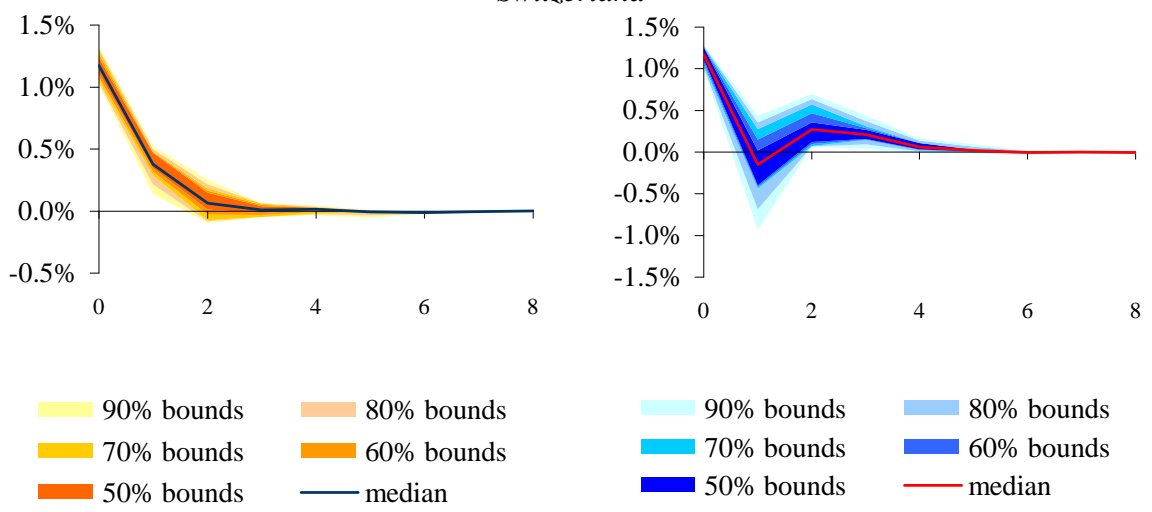

Figure 15: Impulse response function to a shock to risk aversion (median and up to 90\% quantile ranges) on selected major floaters' real effective exchange rate 
Pre-EMU

Post-EMU

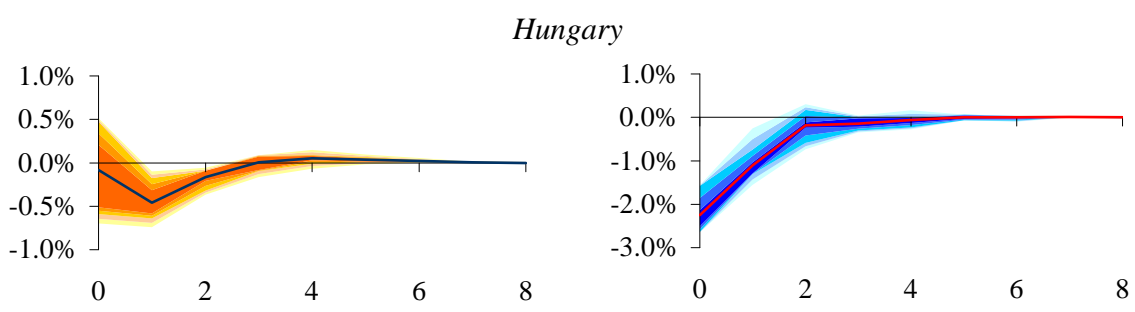

Poland

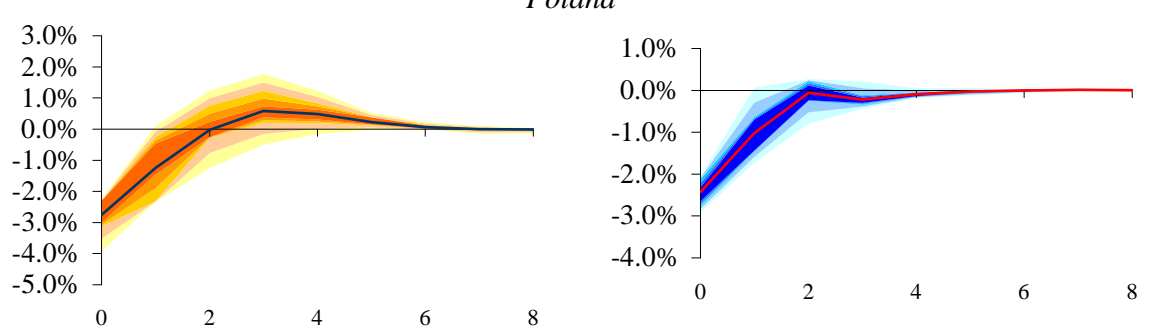

Romania

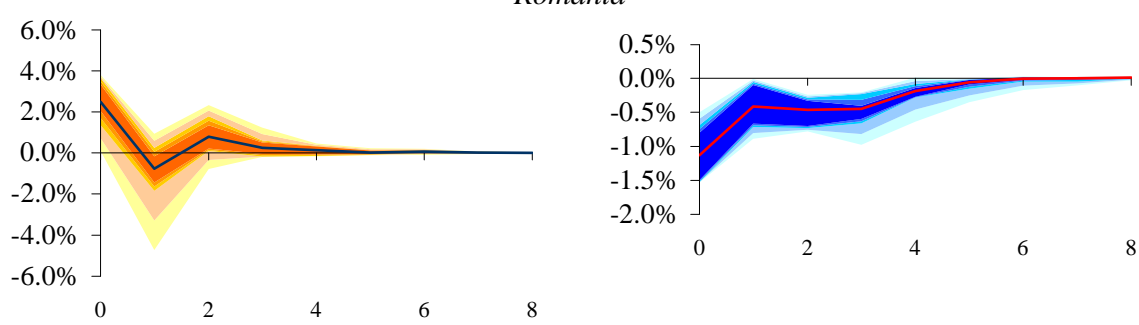

Iceland
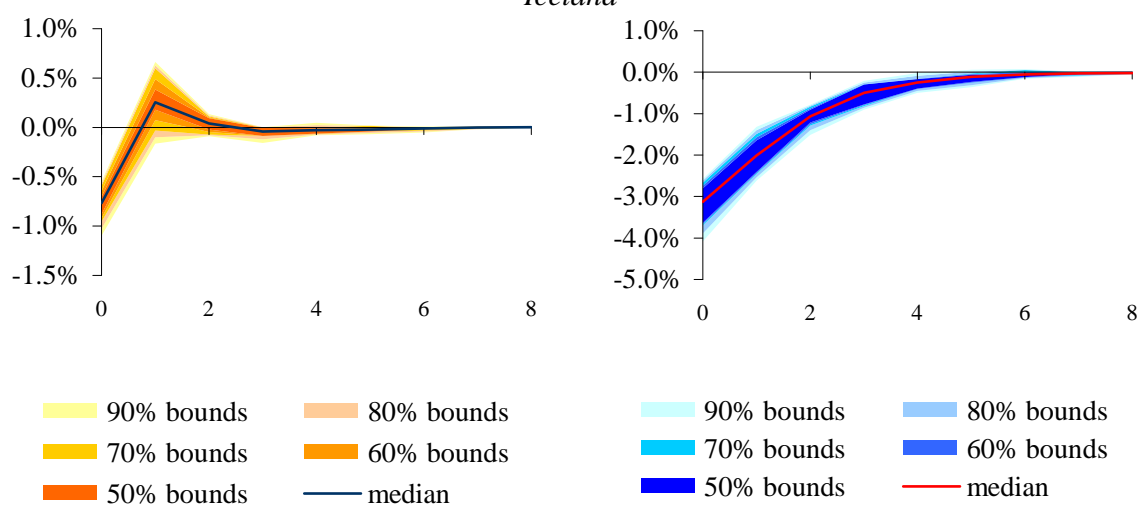

Figure 16: Impulse response function to a shock to risk aversion (median and up to $90 \%$ quantile ranges) on selected new EU Member States and Iceland's real effective exchange rate 
Table 5: Measures of euclidian distance between impulse response functions: Results for generalised shocks to Canada, Japan and the United Kingdom

\begin{tabular}{|c|c|c|c|c|c|c|c|c|c|}
\hline \multirow[b]{2}{*}{ Country $i$} & \multirow[b]{2}{*}{$\eta_{i}^{C A}$} & \multirow[b]{2}{*}{$\eta_{i}^{J A}$} & \multirow[b]{2}{*}{$\eta_{i}^{U K}$} & \multirow[b]{2}{*}{$\xi_{D E, j}^{C A}$} & \multirow[b]{2}{*}{$\xi_{D E, j}^{J A}$} & \multirow[b]{2}{*}{$\xi_{D E, j}^{U K}$} & \multicolumn{3}{|c|}{ No. of rejections for } \\
\hline & & & & & & & $\xi_{i j}^{C A}$ & $\xi_{i j}^{J A}$ & $\xi_{i j}^{U K}$ \\
\hline Austria & $0.15(0.25)$ & $0.24(0.21)$ & $0.23(0.30)$ & $0.25(0.74)$ & $0.16(0.60)$ & $0.38(0.99)$ & 0 & 5 & 3 \\
\hline Belgium & $0.22(0.25)$ & $0.27(0.24)$ & $0.26(0.31)$ & $0.20(0.77)$ & $0.09(0.58)$ & $0.27(0.91)$ & 1 & 3 & 1 \\
\hline Finland & $0.57(0.52)$ & $0.14(0.42)$ & $0.94(0.57)$ & $0.56(1.03)$ & $0.28(0.57)$ & $0.64(1.36)$ & 2 & 0 & 4 \\
\hline France & $0.20(0.21)$ & $0.26(0.21)$ & $0.23(0.29)$ & $0.18(0.74)$ & $0.09(0.53)$ & $0.26(0.85)$ & 0 & 2 & 0 \\
\hline Germany & $0.15(0.61)$ & $0.12(0.51)$ & $0.23(0.72)$ & $0.15(0.61)$ & $0.12(0.51)$ & $0.23(0.72)$ & 0 & 0 & 0 \\
\hline Ireland & $0.12(0.27)$ & $0.19(0.34)$ & $0.70(0.48)$ & $0.22(0.61)$ & $0.24(0.47)$ & $0.47(1.09)$ & 0 & 0 & 1 \\
\hline Italy & $0.56(0.41)$ & $0.15(0.41)$ & $0.74(0.54)$ & $0.14(1.04)$ & $0.09(0.54)$ & $0.25(1.38)$ & 2 & 0 & 4 \\
\hline Luxembourg & $0.29(0.28)$ & $0.32(0.26)$ & $0.40(0.33)$ & $0.26(0.89)$ & $0.15(0.70)$ & $0.39(1.13)$ & 5 & 6 & 8 \\
\hline Netherlands & $0.17(0.23)$ & $0.39(0.21)$ & $0.34(0.28)$ & $0.18(0.69)$ & $0.15(0.57)$ & $0.22(0.95)$ & 0 & 4 & 3 \\
\hline Portugal & $0.11(0.19)$ & $0.20(0.18)$ & $0.22(0.23)$ & $0.39(0.75)$ & $0.38(0.45)$ & $0.55(0.91)$ & 0 & 1 & 1 \\
\hline Spain & $0.30(0.27)$ & $0.04(0.27)$ & $0.52(0.33)$ & $0.25(0.89)$ & $0.13(0.44)$ & $0.36(1.23)$ & 2 & 0 & 6 \\
\hline Greece & $0.09(0.23)$ & $0.34(0.22)$ & $0.28(0.26)$ & $0.21(0.65)$ & $0.12(0.65)$ & $0.28(0.94)$ & 0 & 6 & 2 \\
\hline
\end{tabular}

Notes: $C A, J A$, and $U K$, stands for Canada, Japan and United Kingdom, respectively. $\eta_{i}^{\ell}$, for $\ell \in\{C A, J A, U K\}$ is the euclidean distance between the impulse responses to a generalized shock to country-equation $\ell$ and for euro area country $i$ before and after EMU; see (8). The $90 \%$ critical values reported in parentheses for hypothesis (9) that the distance is zero are computed by bootstrap replications under the null of no structural break; $\xi_{D E, j}^{\ell}$ is the euclidian distance between the impulse responses to a generalized shock to country-equation $\ell$ and for euro area country $j$ after EMU and that for Germany before EMU; see (10). The $90 \%$ critical values reported in parentheses are calculated by bootstrap replications for the null hypothesis (11) that the distance is not larger; $\xi_{i j}^{\ell}$ is the euclidian distance between the impulse responses to a generalized shock to country-equation $\ell$ and for euro area country $j$ after EMU and euro area member $i$ before EMU; the column reports the number of countries for which the null that the distance is smaller is rejected. 


\section{References}

Adrian, T., E. Etula, and H. S. Shin (2010). Risk appetite and exchange rates. FRB of New York Staff Report No. 361.

Andrews, D. W. K. and W. Ploberger (1994). Optimal tests when a nuisance parameter is present only under the alternative. Econometrica 62(6), 1383-1414.

Artis, M. J., D. Osborn, and P. J. Perez (2006). The international business cycle in a changing world: volatility and the propagation of shocks in the G-7. Open Economies Review 17(3), 255-279.

Baldwin, R. (2006). The euro's trade effect. ECB Working Paper No. 594.

Berger, H. and V. Nitsch (2010). The euro's effect on trade imbalances. IMF Working Paper 10/226.

Blanchard, O. and G. M. Milesi-Ferretti (2009). Global imbalances: In midstream? IMF Staff Position Note SPN/09/29, International Monetary Fund.

Canova, F., M. Ciccarelli, and E. Ortega (2006). Similarities and convergence of G-7 cycles. Journal of Monetary Economics 54(3), 850-878.

Cappiello, L., A. Kadareja, and S. Manganelli (2009). The impact of the euro on equity markets: a country and sector decomposition. Journal of Financial and Quantitative Analysis 45(2), 473-502.

Cecchetti, S. G., A. Flores-Lagunes, and S. Krause (2005). Assessing the sources of changes in the volatility of real growth: Rba annual conference volume. In C. Kent and D. Norman (Eds.), The Changing Nature of the Business Cycle,, pp. 115-138. Reserve Bank of Australia: Sydney.

Chudik, A. and M. H. Pesaran (2011a). Econometric analysis of high dimensional VARs featuring a dominant unit. Econometric Reviews.

Chudik, A. and M. H. Pesaran (2011b). Infinite dimensional VARs and factor models. Journal of Econometrics $163,4-22$.

Chudik, A., M. H. Pesaran, and E. Tosetti (2011). Weak and strong cross section dependence and estimation of large panels. Econometrics Journal 14, C45-C90.

Coeurdacier, N. and P. Martin (2009). The geography of asset trade and the euro: insiders and outsiders. Journal of the Japanese and International Economies 23(2), 90-113.

Dees, S., M. H. Pesaran, L. V. Smith, and R. P. Smith (2010). Supply, demand and monetary policy shocks in a multi-country new keynesian model. CESifo Working Paper Series No. 3081.

DeSantis, R. and B. Gerard (2009). International portfolio reallocation: Diversification benefits and European monetary union. European Economic Review 53, 1010-1027.

Dées, S., F. di Mauro, M. H. Pesaran, and L. V. Smith (2007). Exploring the international linkages of the euro area: a Global VAR analysis. Journal of Applied Econometrics 22, 1-38.

Enders, Z., P. Jung, and G. J. Müller (2009). Has the euro changed the business cycle? University of Bonn Discussion Paper, 06/2009.

Engel, C. and J. H. Rogers (2002). European product market integration after the euro. Economic Policy 19, $347-384$.

European Central Bank (2008). Monthly Bulletin - 10th Anniversary of the ECB. European Central Bank.

European Commission (2008). EMU@10: Successes and challenges after 10 years of Economic and Monetary Union. European Commission. Communication from the Commission to the European Parliament, the Council, the European Economic and Social Committee, the Committee of the Regions and the European Central Bank.

Giavazzi, F., A. Giovannini, D. Begg, and L. Katseli (1986). The EMS and the Dollar. Economic Policy 1(2), $455-485$.

Giavazzi, F. and L. Spaventa (2010). Why the current account matters in a monetary union: lessons from the financial crisis in the euro area. CEPR Discussion Papers 8008. 
Goldberg, L. S. (2010, January). Is the international role of the dollar changing? Current Issues in Economics and Finance 16(1), 1-7. Federal Reserve Bank of New York.

Hausman, J. A. (1978). Specification tests in econometrics. Econometrica 46, 251-272.

Holly, S., M. H. Pesaran, and T. Yamagata (2010). Spatial and temporal diffusion of house prices in the UK. CESifo Working Paper No. 2913.

International Monetary Fund (2005, September). World Economic Outlook. International Monetary Fund.

International Monetary Fund (2008, April). Dollar Depreciation and Commodity Prices. International Monetary Fund. World Economic Outlook, 48-50.

Jaumotte, F. and P. Sodsriwiboon (2010). Current account imbalances in the southern euro area. IMF Working Papers 10/139.

Koop, G., M. H. Pesaran, and S. M. Potter (1996). Impulse response analysis in nonlinear multivariate models. Journal of Econometrics 7/4, 119-147.

Lane, P. (2006). Global bond portfolios and EMU. International Journal of Central Banking 2(2), 1-23.

McCauley, R. N. and P. McGuire (2009). Dollar appreciation in 2008: Safe haven, carry trades, dollar shortage and overhedging. BIS Quarterly Review, 85-93.

Mihov, I. (2001). Monetary policy implementation and transmission in the european monetary union. Economic Policy 16, 369-406.

Nyblom, J. (1989). Testing for the constancy of parameters over time. Journal of the American Statistical Association 84, 223-230.

Obstfeld, M. and K. Rogoff (2005). Global current account imbalances and exchange rate adjustments. Brookings Papers on Economic Activity 1, 67-123.

Obstfeld, M. and K. Rogoff (2009). Global imbalances and the financial crisis: Products of common causes. CEPR Discussion Papers No. 7606.

Pesaran, M. H. (2006). Estimation and inference in large heterogenous panels with multifactor error structure. Econometrica 74, 967-1012.

Pesaran, M. H., T. Schuermann, and S. Weiner (2004). Modelling regional interdependencies using a global error-correcting macroeconometric model. Journal of Business and Economics Statistics 22, 129-162.

Pesaran, M. H. and Y. Shin (1998). Generalized impulse response analysis in linear multivariate models. Economics Letters 58, 17-29.

Ploberger, W. and W. Krämer (1992). The CUSUM test with OLS residuals. Econometrica 60(2), 271-286.

Popescu, A. and F. Smets (2010). Uncertainty, risk-taking, and the business cycle in germany. CESifo Economic Studies 56, 596-626.

Quandt, R. E. (1960). Tests of the hypothesis that a linear regression system obeys two separate regime. Journal of the American Statistical Association 55, 324-330.

Rogers, J. (2007). Monetary union, price level convergence, and inflation: How close is Europe to the USA? Journal of Monetary Economics 53(3), 785-796.

Stock, J. H. and M. W. Watson (2002). Has the business cycle changed and why? NBER Working Paper No. 9127.

Taylor, M., D. Peel, and L. Sarno (2001). Nonlinear mean-reversion in real exchange rates: Toward a solution to the purchasing power parity puzzles. International Economic Review 42(4), 1015-1042.

Wolf, M. (2010, September). Germans are wrong: the eurozone is good for them. Financial Times.

Wu, D. M. (1973). Alternative tests of independence between stochastic regressors and disturbances. Econometrica 41, 733-750. 


\section{A Additional Tables and Figures}

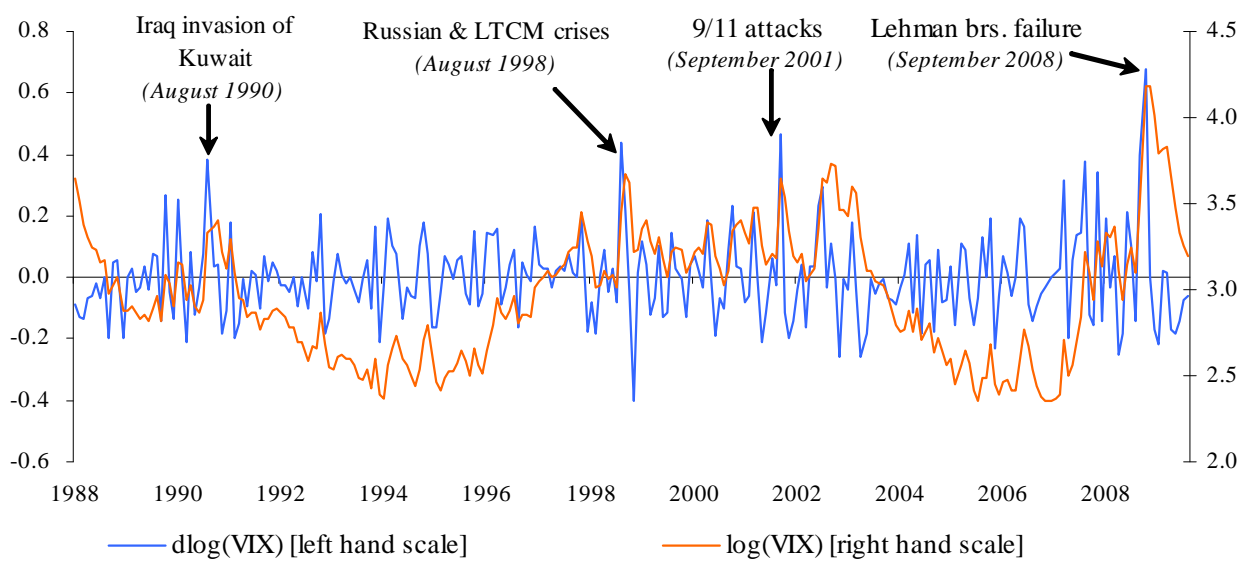

Figure A.1: Selected historical episodes of heightened risk aversion and increases in the VIX index

Table A.1: Change in real effective exchange rates and level of the VIX during selected historical episodes of heightened risk aversion

\begin{tabular}{rrrrr}
\hline \hline & $\begin{array}{c}\text { Lehman brs. } \\
\text { failure } \\
\text { Sep - Oct 2008 }\end{array}$ & $\begin{array}{c}\text { attacks } \\
\text { Sep-01 }\end{array}$ & $\begin{array}{c}\text { Russian and } \\
\text { LTCM crises } \\
\text { Aug - Sep 1998 }\end{array}$ & $\begin{array}{c}\text { Iraq invasion } \\
\text { of Kuwait } \\
\text { Aug 1990, }\end{array}$ \\
\hline United States & $9.2 \%$ & $0.4 \%$ & $0.2 \%$ & $-1.8 \%$ \\
Canada & $-8.6 \%$ & $-1.9 \%$ & $-2.7 \%$ & $-0.4 \%$ \\
Japan & $15.4 \%$ & $1.6 \%$ & $3.3 \%$ & $-0.7 \%$ \\
Australia & $-21.7 \%$ & $-3.8 \%$ & $-7.2 \%$ & $-0.4 \%$ \\
New Zealand & $-4.8 \%$ & $-2.2 \%$ & $-3.8 \%$ & $1.0 \%$ \\
United Kingdom & $-1.3 \%$ & $0.9 \%$ & $-0.9 \%$ & $2.3 \%$ \\
Switzerland & $3.4 \%$ & $1.6 \%$ & $3.7 \%$ & $3.3 \%$ \\
Germany & $-4.5 \%$ & $0.3 \%$ & $2.0 \%$ & $0.7 \%$ \\
France & $-4.2 \%$ & $0.2 \%$ & $1.4 \%$ & $0.9 \%$ \\
Korea & $-20.9 \%$ & $-1.6 \%$ & $-7.8 \%$ & $-1.1 \%$ \\
Iceland & $-21.1 \%$ & $-1.8 \%$ & $-1.3 \%$ & $-0.3 \%$ \\
Poland & $-7.8 \%$ & $-0.1 \%$ & $-7.0 \%$ & $-2.2 \%$ \\
& & & & \\
VIX & 98.7 & 38.6 & 70.7 & 27.8 \\
\hline \hline
\end{tabular}

Notes: As a motivation for the sign restrictions chosen for the identification of risk aversion shocks, the table reports changes in real effective exchange rates during selected historical episodes of heightened risk aversion for the currencies sign-restricted under the identification scheme - and for the sake of comparison - the level of the VIX index during those episodes 


\section{Table A.2: IMF IFS database: overview of missing data and comparison with BIS data- base}

\begin{tabular}{rccc}
\hline \hline & Gaps (in first differenced series) & Correlation \\
\cline { 2 - 3 } & Missing period & No.of obs. & with BIS data \\
\hline Australia & 9 gaps between June 03 - June 08 & 50 & $99.2 \%$ \\
Canada & 7 gaps between October 03 - October 2008 & 17 & $97.6 \%$ \\
Germany & October 03 - November 03 & 2 & $94.8 \%$ \\
Greece & 2 gaps between September 03 - May 04 & 5 & $57.1 \%$ \\
Ireland & 2 gaps between July 03 - March 06 & 32 & $98.1 \%$ \\
Italy & 3 gaps between October 03 - June 06 & 6 & $97.7 \%$ \\
Japan & 4 gaps between March 04 - October 08 & 9 & $98.9 \%$ \\
Netherlands & October 03 - November 03 & 2 & $92.6 \%$ \\
Poland & 3 gaps between September 04 - October 05 & 9 & $93.0 \%$ \\
Portugal & 3 gaps between October 03 - December 06 & 7 & $52.4 \%$ \\
Saudi Arabia & 4 gaps between August 03 - October 08 & 21 & $97.8 \%$ \\
\hline \hline
\end{tabular}

Notes: We include all (45) countries in the IMF IFS database for which real effective exchange rate data for the period January 1988 - August 2009 are available, including: Algeria, Antigua and Barbuda, Austria, The Bahamas, Kingdom of Bahrain, Belgium, Belize, Bolivia, Chile, P.R. China, Colombia, Costa Rica, Denmark, Dominica, Ecuador, Equatorial Guinea, Finland, France, Gabon, Gambia, Ghana, Hungary, Iceland, Iran, Israel, Luxembourg, Malaysia, Malta, Morocco, New Zealand, Norway, Pakistan, Philippines, Romania, Solomon Islands, South Africa, Spain, Kitts and Nevis, Sweden, Switzerland, Trinidad and Tobago, Tunisia, United Kingdom, United States and Zambia. A number of euro area or other systemically important countries are missing from this list because the IMF IFS database has no or missing data in their case. We interpolate missing observations using BIS indices (see Table A.2 for details). In addition, we have included Argentina, India, Indonesia, Korea, Mexico and Thailand from this latter database since they are important emerging markets. We have taken to that end broad BIS 58-country indices from January 1994 onwards. Data prior 1994 were constructed using data on nominal exchange rates, consumer price indices (both taken from the IMF IFS database) and trade weights taken as constructed from the IMF DOTS database. Historical correlations are computed with the first log differences of the real effective exchange rate indices between February 1994 (starting date for BIS series) to the first gap in the corresponding series in the IMF IFS database. 


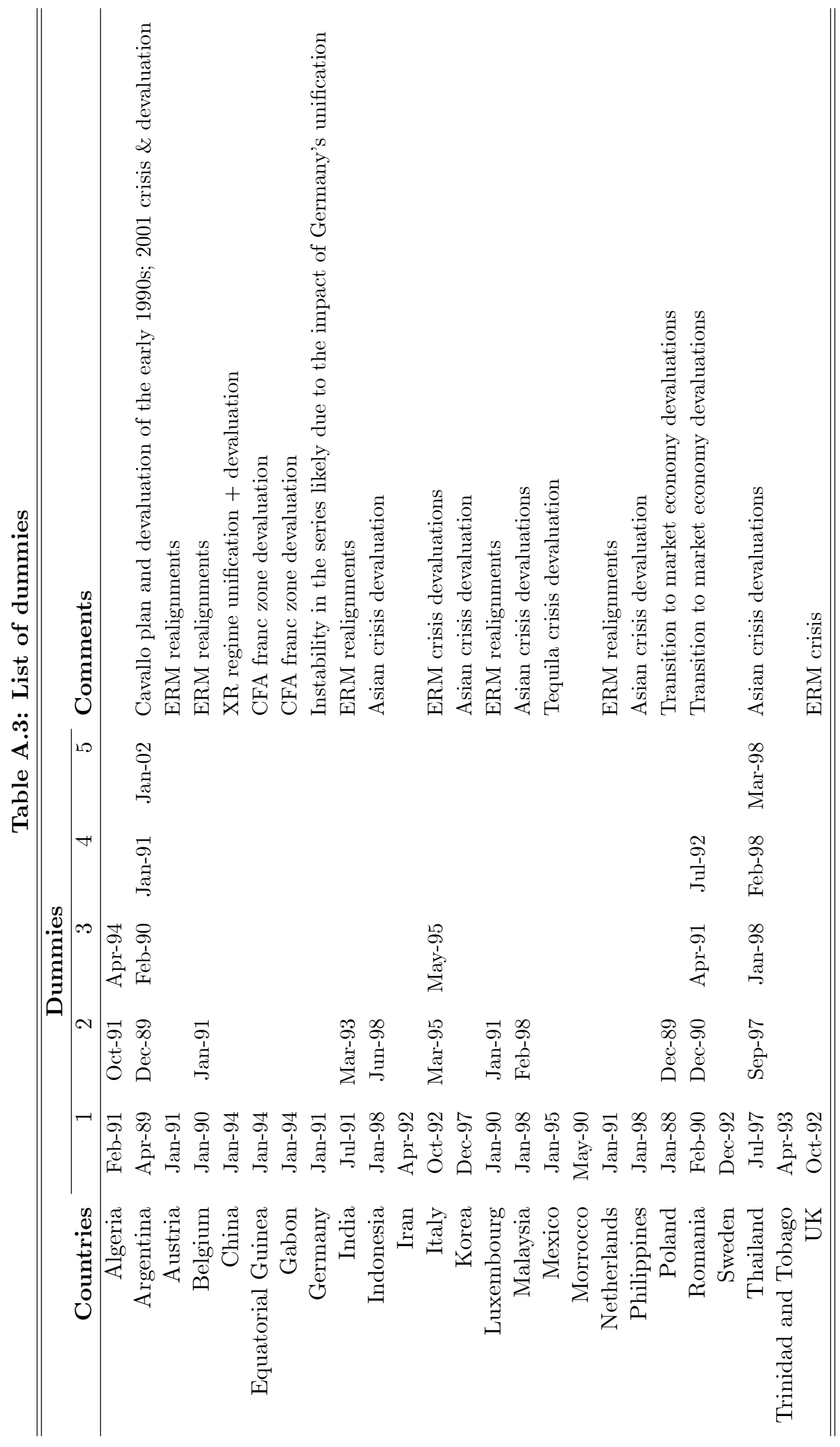

